\title{
Investigation of Bingöl Iron Ore Reserves Using Wavelet Cellular Neural Networks
}

\author{
Ali Muhittin Albora* \\ Istanbul University-Cerrahpasa, Engineering Faculty, \\ Geophysical Department, 34555 Hadimkoy, Istanbul, Turkey \\ *correspondence: Ali Muhittin Albora; muhittin@istanbul.edu.tr
}

\begin{abstract}
In the current study, the performance of a synthetic wavelet CNN (Wave-CNN) was tested and then compared with geophysical field data; two separate synthetic studies were conducted for this purpose. In the first synthetic application, the success of the Wave-CNN method for the separation of regional-residual dipole structures was tested. In the second synthetic application, using prismatic structures with magnetic properties, the success of the Wave-CNN method to determine boundaries was compared with classical methods. It was found that the Wave-CNN method could not be repeated as many times as required. At first, it was possible to distinguish between regional and residual anomalies and successfully determine boundaries. As the number of repetitions increased, it was possible to clarify structures with stronger magnetic properties and to filter out structures with weak magnetic properties. The Wave-CNN using a vertical component of the magnetic field method was then applied to magnetic anomaly data from three Avnik iron mines located in the Bingöl Province, East Anatolia, Turkey: these areas are called, from south-to-north, Gonactepe, Heylandere and Miskel. The Wave-CNN outputs were also compared to drilling results from the study areas. Using this method, Wave-CNNs can be used to solve geophysical problems by detecting surface layer boundaries. In this Avnik field application, the Wave-CNN results showed high anomaly values indicating probable an iron ore deposit. In addition, represantive anomaly values were selected from the Wave-CNN outputs of each subarea and forward modeling was performed by applying Differential Evolution (DE) method. Thus, it has been shown that a good relation is obtained with the geological cross-section and geophysical model structures.
\end{abstract}

Keywords: wavelet cellular neural network; image processing; iron ore; forward modelling

\section{INTRODUCTION}

Magnetic anomaly analysis is used for geophysical applications, such as boundary detection and determining ore reserves. As well as classical geophysical techniques, artificial-intelligence neural network-based image-processing techniques have become useful. Recently, cellular neural networks (CNNs) have been used in geophysical studies with very good results; the CNN's filtering performance provides parallel calculation for geophysical image processing. A $\mathrm{CNN}$ is a supervised learning algorithm that uses two matrices defined by a template. First, a learning algorithm is applied to geophysical measurements and a combined learning algorithm is then developed from a synthesis of the CNN learning and processing. Wavelet functions and backpropagation learning algorithms can be used to increase training speed.

One of the most important problems for geophysics is the separation of regional and residual anomalies of potential fields and the determination of structural boundaries. As an alternative method, a wavelet transform has been widely used to model potential fields (Davis et al. 1994; Fedi and Quarta 1998; Ridsdill-Smith and Dentith 1999; Ucan et al. 2000 and Alp et al. 2011). The wavelet method, used with local potential anomaly maps, is suitable for separating regional and residual anomaly maps (Fedi and Quarta 1998; Hornby et al. 1999). Several parameters associated with geological structures have been calculated using multi-scale edge analysis Holden et al. (2000) and boundaries of embedded structures have been determined by applying noise analysis Boschetti et al. (2001). Magnetic anomalies obtained from archaeological sites using the enhanced horizontal derivative method with the wavelet method have been used to find the edges of structures and boundaries and parameters of archaeological structures have also been determined using the wavelet method for archaeological sites (Fedi and Florio 2003; Albora et al. 2004). The wavelet method has been used for the determination of structural borders (Alp et al. 2011).

Cellular neural networks (CNNs) were proposed by Chua and Yang (1988) and the development of recurrent learning algorithms for stable CNNs was proposed by (Matsumoto et al. 1990; Slot 1992; Chua and Roska 2002). The CNN method was used for the first time to solve geophysical problems by separating regional and residual anomalies by Albora et al. (2001a, 2001b). A CNN was used to reveal fault lines in the Lakes Region, Western Anatolia and to model synclinal and anticlinal structures (Albora et al. 2007a).

In previous studies aeromagnetic data were modeled in 2.5 dimensions (Fedi et al. 1998), while other authors applied forward modelling by using forced neural networks method in potential sources (Osman et al. 2015; Osman et al. 2007). 
They showed the efficiency of magnetic anisotropy by solving magnetic data with inverse solution (Liu et al. 2018). They modeled the gravity and magnetic anomaly of fault-shaped structures using Differential Evolution versus Particle Swarm Optimization method (Ekinci et al. 2019).

\section{METHOD}

In the current study, two different synthetic studies were conducted to test the success of the wavelet CNN (WaveCNN) method for magnetic methods. The first synthetic work was a regional-residual separation of dipole constructions. In the second synthetic work, it was used to determine the structural boundaries of three different prisms and to separate a boundary structure in a magnetic anomaly map obtained from the Bingöl mine site. WaveCNN method regional and residual separation acquired better results than classical methods. The Wave-CNN anomaly maps were correlated with drilling results.

\section{- Wavelet-Cellular Neural Network}

The emergence of superior features of the wavelet theory in comparison with the classical methods in signal and image separation has led the researchers to work intensively in this field. In Artificial Neural Networks, successful results in signal and image processing applications have enabled the studies on the use of these two methods together. In this study, wavelet transform is used in preprocessing unit for feature extraction. The feature vectors obtained in this unit form the input set of artificial Neural Networks. It has been seen that the feature vectors obtained as a result of wavelet transform give very good results in applications using this structure. The properties of wavelet functions allow the lossless analysis of signals. In order to examine the contribution of this analysis feature to convergence in artificial neural networks, the use of wavelet functions as activation functions was realized. Firstly, the most appropriate wavelet function search has been made. At the end of the study, the selected wavelet function was used in forward multilayer network structure. This new network is called the Wavelet Artificial Neural Network (Wave-CNN).

The Wavelet Artificial Neural Network consists of a hidden layer and an output layer. Wavelet function is used in the hidden layer of this network and linear function is used in the output layer. (Wave-CNN) 's backpropagation algorithm was used in the training. It is mandatory that the activation functions can be derived from the operation of this algorithm. Log-sigmoid, hyperbolic tangent sigmoid and linear functions are used as activation functions in multilayer networks that are widely used. The selection of the wavelet function requires that the derivative is obtainable and that it can be used in the back propagation algorithm. Haar wavelet is not preferred because it is not continuous. As a result of studies on Morlet wavelet and Mexican hat functions, it has been observed that Mexican hat provides high performance.

This function can be expressed as;

$$
\psi=\left(1-x^{2}\right) e^{-x^{2}}
$$

The expression of the linear function used in the output layer of Wave-CNN is given as $\mathrm{y}=\mathrm{x}$.

The forward propagation expression of the Wave-CNN method is as follows (Figure 1);

$$
y=w^{2}\left(\psi\left(w^{1} x+b^{1}\right)\right)+b^{2}
$$

Here; $w^{1}$ : Link weight matrix for the first layer, $x$ :Input set, $w^{2}$ : connection weights (wavelet coefficients) between wavelet neurons and output, $b^{1}$ and $b^{2}$ : threshold values in each layer, $\psi$ :wavelet function.

The aim of training of artificial neural networks is that the relationship between the targeted outputs and the input set can be expressed by a correlation of activation functions, weight coefficients and threshold values. The limiting measure in establishing this relationship is the error rate between the outputs of the network and the targeted values. It adjusts the weight coefficients in steps to minimize this error during network training.

The purpose of the Wave-CNN method is to assume that the translation and scaling properties used in the analysis of these functions will increase the convergence rate. The convergence rate means that the error is minimized in a short time and network training is completed in a shorter time.

Cellular Neural Network (CNN) is a two dimensional array of cells. These cells are in connection with only surrounding cell illustrated with a $4 \times 4$ cellular artificial neural network.

(Figure 2). The main function of the CNN is converted to an output image in accordance with the intended purpose of any input image. Considering the initial state value of each pixel of the output image CNN is limited to be -1 and +1 (Figure 3). In case of all cells are set to start, the calculation remains in a fixed position when no cells change their output states. CNN is stable convergence in the cells that depends on the deviation values and the appropriate template factors. CNN parameter values are assumed to be spacedinvariant and the nonlinear function is chosen as piece-wise linear. A, B, and I are cloning template matrices that are identically repeated in the neighborhood of every neuron as (see for details; Chua and Yang 1988; Matsumoto et al. 1990; Slot 1992; Hagan et al. 1995; Albora et al. (2001a, 2001b); Chua and Roska 2002, Ucan et al 2002).

In the CNN method, each cell has an architecture consisting of a linear input unit, a linear dynamic interface, and a symmetrical output unit based on the n-part origin (Figure 4).

$A=\left[\begin{array}{ccc}a_{-1,-1} & a_{-1,0} & a_{-1,1} \\ a_{0,-1} & a_{0,0} & a_{0,1} \\ a_{1,-1} & a_{1,0} & a_{1,1}\end{array}\right], B=\left[\begin{array}{ccc}b_{-1,-1} & b_{-1,0} & b_{-1,1} \\ b_{0,-1} & b_{0,0} & b_{0,1} \\ b_{1,-1} & b_{1,0} & b_{1,1}\end{array}\right], \quad I$

Wavelet theory and learning in the feedforward network algorithms are used (see for details; Grossman and Morlet, 1985; Daubechies, 1990; Akansu, and Haddad 1992; Rao and Bopardikar, 1998; Albora and Ucan, 2001). In feedforward networks with wavelet functions as a result of research on this subject it has been studied on the use of back-propagation algorithm. The new learning algorithm, was named wavelet learning algorithm, is obtained as a result of these two methods. They are applied to the CNN method. The smaller CNN architecture was built using this learning algorithm. This architecture is called Wave-CNN (see for details; Albora et al. 2007b). In Wave-CNN, one of the main problems is to find the best suited A, B and I templates for the real problem.

Step 1. The feedback property of the CNN should be transferred to feedforward form. Step 2. The other critical point to be solved is to arrange the output non-linear function such that derivative property can be held. So, we have preferred wavelet functions.

Step 3. The last step is altering the matrix form of A, B, and I template into vectoral form. 
Thus, we are able to start training by Back-Propagation algorithm. The main equation is as follows:

$E(\omega)=\frac{1}{2} \sum_{N} \sum_{i, j}\left(y_{i, j}^{k}(\infty)-t_{i, j}^{k}\right)^{2}$

where $\quad \mathrm{y}_{\mathrm{i}, \mathrm{j}}(\infty) \quad$ are steady state of Artificial Neural Network (ANN) output. In stable case, the network output will take only $[-1,1]$ values and training procedure is ended. For the average minimum error criteria, we use steepest descent algorithm as follows,

$\omega(\mathrm{k}+1)=\omega(\mathrm{k})-\alpha \cdot \frac{\partial \mathrm{E}(\omega)}{\partial \omega^{\mathrm{k}}}$

In partial derivative approach, Eq. 4 can be rewritten as (Hagan et al. 1995).

$$
\frac{\partial \mathrm{y}_{\mathrm{i}, \mathrm{j}}^{\mathrm{k}}(\infty)}{\partial \omega^{\mathrm{k}}}=\frac{\partial \mathrm{F}\left(\mathrm{x}_{\mathrm{i}, \mathrm{j}}^{\mathrm{k}}(\infty)\right)}{\partial \mathrm{x}_{\mathrm{i}, \mathrm{j}}^{\mathrm{k}}(\infty)} \frac{\partial \mathrm{x}_{\mathrm{i}, \mathrm{j}}^{\mathrm{k}}(\infty)}{\partial \omega^{\mathrm{k}}}
$$

The derivative of $\mathrm{F}$ function is as ( $\mathrm{F}$ is the error function expression of the network structure.),

$$
\mathrm{F}^{\prime}(\mathrm{x})=\left\{\begin{array}{cc}
0 & \mathrm{x} \leq-1 \text { and } \mathrm{x} \geq 1 \\
1 & -1<\mathrm{x}<1
\end{array}\right\}
$$

We have used Mexican Hat function among wavelet functions (Figure 5), which suit Eq. 7 (see for details; Albora et al. 2007b).

$$
\psi=\left(1-\mathrm{a} \cdot \mathrm{t}^{2}\right) \mathrm{e}^{-\mathrm{bt} \mathrm{t}^{2}}
$$

Replacing Eq. 8 for the case of $\mathrm{a}=0.1$ and $\mathrm{b}=2$ in Eq.5, we obtain the following equation,

$\omega(\mathrm{k}+1)=\omega(\mathrm{k})-\alpha \mathrm{Y}_{\mathrm{i}, \mathrm{j}}^{\mathrm{k}} \cdot\left(1-0.1 \mathrm{x}_{\mathrm{i}, \mathrm{j}}{ }^{\mathrm{k}}\right) \mathrm{e}^{-2 \mathrm{x}_{\mathrm{i}, \mathrm{k}}{ }^{\mathrm{k}}} \cdot\left(\mathrm{y}_{\mathrm{i}, \mathrm{j}}^{\mathrm{k}}(\infty)-\mathrm{t}_{\mathrm{i}, \mathrm{j}}^{\mathrm{k}}\right)$

where, iteration number $=\mathrm{k}$;

$(\mathrm{k}+1)$ instant weight value $=\omega(\mathrm{k}+1)$;

$(\mathrm{k})$ instant weight value $=\omega(\mathrm{k})$;

Training ratio $=\alpha$; Input matrix $=\mathrm{Y}_{\mathrm{i}, \mathrm{j}}^{\mathrm{k}}$; Initial matrix $=\mathrm{x}_{\mathrm{i}, \mathrm{j}}^{\mathrm{k}}$;

Stable output of Wave-CNN after kth iteration= ${ }_{\mathrm{i}, \mathrm{j}}^{\mathrm{k}}(\infty)$; The desired output matrix $=\mathrm{t}_{\mathrm{i}, \mathrm{j}}^{\mathrm{k}}$.

\section{- Wave-CNN Applications on Synthetic Data}

In the learning procedure, using $A, B$ and $I$ template elements in Eq. 8, they have been obtained Eq. 10.

$\mathrm{A}=\left[\begin{array}{ccc}-0.5766 & 0.0146 & -0.3126 \\ 0.0146 & -1.4335 & 0.0146 \\ -0.3126 & 0.0146 & -0.5766\end{array}\right], \mathrm{B}=\left[\begin{array}{rrr}0.7281 & 0.1410 & -0.0694 \\ 0.1410 & -0.0668 & 0.1410 \\ -0.0694 & 0.1410 & 0.7281\end{array}\right], \mathrm{I}=-1.3294$

Wave-CNN, approximately 10000-100000 replication interval of other feed forward neural networks only to the desired output for 10-100 replication reduces the time it takes to reach the training.

We examined two-dimensional structure of a magnetic dipole, as shown in Figure 6. Here, $\mathrm{Z}$ is the vertical component of the field, can be written as (Telford et al. 1990),

$\mathrm{Z}=$ (Vertical component of field due to $-\mathrm{m})$ - (Vertical component of field due to $+\mathrm{m}$ )

$$
\begin{aligned}
& \mathrm{Z}=\mathrm{kF}_{0} \mathrm{~S}\left\{\left(\frac{1}{\mathrm{r}_{1}^{2}}\right)\left(\frac{\mathrm{z}}{\mathrm{r}_{1}}\right)-\left(\frac{1}{\mathrm{r}_{2}^{2}}\right)\left(\frac{\mathrm{z}+\mathrm{L} \sin \alpha}{\mathrm{r}_{2}}\right)\right\} \\
& =k F_{0} S\left\{\left(z / r_{1}^{3}\right)-(z+L \sin \alpha) / r_{2}^{3}\right\} .
\end{aligned}
$$

$\mathrm{k}$ is susceptibility, $F_{\mathrm{o}}$ is earth's total magnetic field and $\mathrm{S}$ is surface area.

Since we have assumed that the rod is magnetized along its axis, these expressions are valid only under following conditions:

(i) the main field of the rod is very much larger than the external field;

(ii) the rod is oriented along the field direction.

Since one type of anomaly often masks another, the need arises to discrete the various anomalies from each other.

The Wave-CNN method was used to test the method of separating of regional and residual anomalies. The second vertical derivative, upward and downward continuation methods for different parameters given in Table I, were applied (Figure 7a). The result of the second vertical derivative, upward and downward continuation in the total magnetic anomaly map, is shown in Figure $7 b, c, d$. The WaveCNN output of the first iteration is shown as an anomaly map in Figure 7e, and the anomaly map of the third iteration is displayed in Figure 7f. The Wave-CNN method provided a more successful distinction than classical methods. With increasing numbers of iterations, the strong magnetic anomaly values remained while the weaker magnetic anomaly values are disappeared (Figure 7e, 7f).

For the second synthetic application (Table II), three different prisms were studied at different coordinates and at different depths (Figure 8). The purpose of this study was to compare the performance of the Wave-CNN method with conventional methods used to determine building boundaries. The total magnetic anomaly contour map of the three prisms is presented in Figure 9a, and a shaded relief map of these contours is shown in Figure 9b. When the derivation map of these prisms was used, the map presented in Figure 9c was obtained. As seen in Figure 9c, the boundaries of the two prisms in the upper part are blurred and the image is distorted. 
The output, shown in Figure 9d, was obtained by applying an edge detection analytical signal method to the total magnetic anomaly, formed edge of prisms. Here, the boundaries of the prisms were not seen. The edge detection horizontal gradient method was then applied (Figure 9e), and the boundaries of the underlying prism were clearly seen; the adjacent edges of the upper prisms could not be separated and two prisms were displayed as if they were an extension of one prism. In the shaded relief map of the Wave-CNN output (Figure 9f), the boundaries of the prisms with three different parameters in the map obtained by this method were very clear. For this application, the Wave-CNN method was a very successful method for boundary detection.

\section{FORWARD MODELLING METHOD}

In this study, two-dimensional forward modeling was performed in order to show that the Wave-CNN method successfully separates the structures from each other and to show that the structure is well modeled. Differential Evolution versus Particle Swarm Optimization inverse solution technique was applied to one of the anomalies giving dipole shaped magnetic anomaly from Wave-CNN outputs of the application field given in formula 11 . Differential Evolution (DE) is used to optimize actual parameters and real-valued functions (Storn, 1996; Storn and Price, 1997).

In DE applications, firstly, some essential parameters, namely population number, crossover probability and the mutation constant (or weighting factor) are selected by the user, and then an initial population is generated The first process begins with mutation, which has several approaches in DE to obtain the donor vector (Storn and Price, 1997). The evolution strategy, including the mutation scheme, the number of difference vectors, and the binomial or exponential, is then selected (Balkaya, 2013). The test vector is obtained using both the donor vector elements and the target vector, and the recombination process combines successful solutions taking into account the previous generation (Balkaya et al., 2017). In the last step, considering the lowest mismatch values, the target vector or test vector is transferred to the next generation (Ekinci, 2016; Essa and ElHussein, 2018; Essa and Munschy, 2019). These operations in the evolutionary cycle continue up to a predefined number of iterations or until a satisfactory objective function value is reached. A flowchart showing the process steps in DE is shown in Figure 10.

\section{REGIONAL GEOLOGY OF THE STUDY AREA}

The study area, Avnik, is located in the Bingöl Province, East Anatolia, Turkey (Figure 11) and the geological map of the region is shown in Figure 12. The Department of Mining Research Institute (MTA) previously conducted magnetic surveys of Avnik to locate iron ore, and the magnetic surveys from the Gonactepe, Haylandere and Miskel fields, within the Avnik region, are discussed.

\section{- Lower Associations}

Lower associations in the Avnik region comprise three rock units: gneisses, felsic and metatuffs. The lower units of the lower associations are gneissic. The grey gneisses include biotite, garnet feldspar-quartz gneisses, magnetite and amphibole rich structures. The base of the gneiss unit is located thickness $1100 \mathrm{~m}$. The upper units of the lower associations are mafic metavolcanites (Helvacl, 1984). Gneiss and metavolcanites containing iron strata are located on the south-west slope of Gonactepe and are cut by granite.

\section{- Upper Associations}

The upper associations in the Avnik region comprise mica schist and marble, and the bottom unit contains mica schist. The lower unit is intruded by the Avnik granitoid, a heterogeneous and strongly albitized rock, which has intrusive and gradational contacts with the metavolcanics, and the Yayla granite a homogeneous body in sharp contact with the surrounding rock (Helvacl, 1984). The white marble unit, which forms the uppermost part of the metamorphic units, is thought to correspond with a Jurassic dolomite unit overlain by discontinuous quartzite. The age of the upper Avnik region geology spans the OrdovicianSilurian to the Jurassic (Erdogan and Dora, 1983).

In the Avnik region, the apatite-bearing iron deposits are intercalated with lensoidal and massively banded metavolcanics of volcano-sedimentary origin. The ore bodies vary along strike and pinch out over short distances because of irregularities on the underlying volcanic topography they were deposited on (Erdoğan and Dora 1983). An important unconformity is located between the lower and upper association levels (Erdoğan 1982). The oldest unit in the upper association, the mica schists, are located on different units of the eroded sub-community or on granites that crosscut them. After sedimentation of the upper association, the region was again folded and metamorphosed during the Cretaceous. In the course of this deformation, the NW-SE axisaligned Gonac anticline was formed (Figure 12). Iron beds extend throughout the anticline structure, and they appear centrally along the NW direction in both wings of the Gonac anticline (Figure 12).

\section{- General Features of the Magnetite-Apatite Avnik Iron Deposits}

The Avnik region was studied in three subareas; Miskel, Heylandere and Gonactepe. A fluxgate magnetometer is used by obtaining the magnetic values. Solar storms, daily changes in ground magnetic field and magnetic corrections were evaluated using the data from Kandilli observatory and Earthquake research institute.

The massive and lenticular-shaped Avnik iron deposits comprise magnetite with small amounts of apatite. Within the magnetite zone, the prevailing ore types occur as amphibolites and metavolcanites. The most important economic iron deposits in the study area are gnays with felsic metatuffs-metavolcanites transition zones (Helvacl, 1984). The oldest rock units in the region are metavolcanites. The metamorphic sequence extending in the SE-NW direction has a thickness of $3000 \mathrm{~m}$. Metatuffs and metavolcanites are important ore deposits. They contain lens-shaped amphibolite schists alternating with the sidewall and are the ore bearing rock units of the Bingöl massif. Other types of rocks carry ore in only small quantities (Erdoğan and Dora 1983). The most important mineralisation is located at Miskel, Heylandere and Gonactepe in the gneissic transition zones with the felsic metatuffs and metavolcanites and along the transition zones of both units. All mineralisation has the same structural characteristic and is compatible with side rock structure (Çelebi 1985). The lenses vary in thickness from 5 to $10 \mathrm{~m}$ and the curved structure is $300 \mathrm{~m}$ (Erdoğan and Dora 1983). The iron ore minerals comprise magnetite and fluorapatite; martitis and hematite is rare. From an economic viewpoint, the most important ores in the Avnik region are iron and phosphorus, and generally, iron reserves are greater than phosphorus reserves (Çelebi 1989).

\section{- The Gonactepe Region}

In the Gonactepe region, 35 parallel profiles were taken at $50 \mathrm{~m}$ intervals. The measurement points on each profile were taken at $25 \mathrm{~m}$ intervals. Maximum 27 measurements and 43 measurements were taken in the profiles and total magnetic anomaly measurements were taken with a fluxgate 
magnetometer at a total of 1395 points. When the complete magnetic anomaly values in Miskel region are examined, a change between $-28000 \mathrm{nT}$ and $26000 \mathrm{nT}$ can be seen (Figure 13).

The Gonactepe deposit comprises magnetite, apatite and actinolite crystals. From drilling results, the ore is $5-10 \mathrm{~m}$ thicker than the granitoids but does not have economic value. These lenticular ore deposits are found associated with magnetite ore: apatite and actinolite. The Gonactepe deposit has an average phosphorus content of $\sim 41 \%$ and a titanium content of $\sim 36 \%$ (Helvacl, 1984).

The mapped magnetic values (Figure 13a) range from $-24,000 \mathrm{nT}$ to $24,000 \mathrm{nT}$. Wave-CNN was applied to the vertical component of the magnetic field in the Gonactepe region. Figures $13 \mathrm{~b}$ and $13 \mathrm{c}$ show the second and third iteration maps, respectively. The cross-section from the third iteration of the Wave-CNN output in Fig. 13c was modeled using the Differential Evolution method using the dipole anomaly approach (Eq 11). Model parameters were approximately $3 \mathrm{~m}$ upper depth $15 \mathrm{~m}$ lower depth and the dipole angle with the earth was found to be 1350 (Table III).

Figure 14 presents the drilling sections for the Gonactepe region; four drill holes (G1, G6, G13 and G21) were available for this region. Sediment cover exists in the region, and the ore tops-up close to the surface and outcrops. Drilling conducted in areas with low anomaly values was designed to detect ore at depth. G1 drilling under $2 \mathrm{~m}$ of sediment was not noticed although it encountered high-grade ore, however, the Wave-CNN output did not detect anomalies in the drill hole. This example demonstrates the success of the Wave-CNN, and in other drilling fields, medium grade ore was found. The geological section (Figure 15a) was taken from where the magnetic section is located, and drill hole G6 is located where the magnetic anomaly is low. The NW-SE oriented magnetic section, A1-A2, (Figure 15b) was constructed from the Wave-CNN output of the vertical component of the magnetic field of the Gonactepe area located on the G6 sounding. Ore is polarised depending on the orientation of the earth's magnetic field, and the ore may be between a minimum anomaly and maximum anomaly depending on the direction of polarisation. Therefore, ore is located in the area of the A1-A2 section where it is negative magnetic anomaly.

\section{- The Heylandere Region}

In Heylandere area a total of 1144 measurement were taken at 26 parallel profiles on $50 \mathrm{~m}$ intervals. The measurement points on each profile were taken at $25 \mathrm{~m}$ intervals and at least 30 and at most 50 points were measured using a fluxgate magnetometer. The Heylandere deposit (Figure 16a) is located in a region of the map containing magnetic anomalies ranging from $-7,000 \mathrm{nT}$ to $17,000 \mathrm{nT}$. In Figure 16b, the magnetic anomaly map of the Wave-CNN method shows the result of the second iteration. The output map obtained from the second iteration of the Wave-CNN method was cross-sectioned immediately next to the $\mathrm{H} 9$ well data and modeled using the differential evolution method using the dipole approach (Eq 11). The distance to the surface is calculated $0.5 \mathrm{~m}$ and the bottom depth is obtained $75 \mathrm{~m}$, while the slope angle was calculated as $150^{\circ}$.

The deposits here have almost the same stratigraphic features as others in the Avnik region; however, the deposit in the Heylandere region is not related to the other deposits. The northern part of the deposit is covered with alluvium. The ore is surrounded by Avnik granitoid, and the rocks are cut by granite, gneiss and amphibolite (Helvacı 1984). Massive iron ore lenses trend NW-SW and are inclined. The iron ore deposit is mainly concentrated around the $\mathrm{H} 9$ drill hole. In addition, Heylandere deposits are connected to the Gonactepe deposit by small lenses.

The Wave-CNN method output analysis resulted in very strong anomaly values. Figure 17 shows the location of the three drill holes used: H1A, H7 and H9. Drillhole H9 is located nearby the anomaly. The best grade ore is observed in the $\mathrm{H} 9$ drill hole. The aim of this drilling, conducted over low anomalies, was to determine whether ore is present at depth. The $\mathrm{H} 7$ drilling was located outside of the strong anomalies in relation to the vertical component of the magnetic field (Figure 16b). The magnetic cross section, B1-B2, was constructed in a SW$\mathrm{NE}$ direction at the exit of the Wave-CNN (Figure 16b) where the $\mathrm{H} 7$ and $\mathrm{H} 9$ bores are located. The geological section (Figure 18a) was oriented in the same direction as the magnetic section (Figure 18b). A high magnetic anomaly was observed in the western part of the H9 sounding. Here, massive magnetite creates a large magnetic effect, and there is good agreement between the geological section and the magnetic section, as shown in Figure 18.

\section{- The Miskel Region}

In the Miskel region, 34 profiles were taken parallel to each other at $50 \mathrm{~m}$ intervals. The measurement points on each profile were taken at $25 \mathrm{~m}$ intervals. 24 and 45 measurements were taken at different profiles and the total magnetic anomaly measurements were taken with a fluxgate magnetometer at a total of 1395 points. When the complete magnetic anomaly values in Miskel region are examined, a change between $-28000 \mathrm{nT}$ and $35000 \mathrm{nT}$ was observed (Figure 19).

The main body of the Miskel ore bed comprises gneisses shaped like metavolcanic rocks. The sounding results showed that the banded ore is found up to $250 \mathrm{~m}$ deep. Disseminated iron occurrences are widespread in the amphibolite, gneiss and other metavolcanic rocks and are usually located adjacent to massive magnetite deposits. Stockwork iron deposits are located mainly adjacent to, or within, the granitoids in the eastern and southeastern part of the Miskel deposit and consist of complex networks of veins containing large crystals of mannetite, apatite and actinolite. The bedded sedimentary iron is mainly composed of granitoids in the eastern and southeastern parts of the Miskel bed and is comprised of a complex network of veins with wide crystals consisting of mannetite, apatite and actinolite. Stockworks also occur above and below the main ore body (Helvacı 1984).

Figure 19a shows the complete magnetic anomaly map of the Miskel region. The Wave-CNN method was applied to this map; the results of the second iteration are presented in Figure $19 \mathrm{~b}$ and the fourth iteration is presented in Figure 19c. The drilling section is very important; the mined, high grade deposit is close to the surface in the area of the Wave-CNN magnetic anomaly map. The model has been generated across the profile where intensive high anomaly is located that is the third iteration of the WaveCNN anomaly. The model structure obtained by dipole approach was used in the Differential Evolution method and its parameters were given in Table III and modeled as vertical dipole with a surface depth of $35 \mathrm{~m}$ and a surface depth of $95 \mathrm{~m}$.

Anomaly maps produced by the Wave-CNN method were compared to the drilling locations (Figure 20). The WaveCNN anomalies corresponded to the highest values. The Miskel vertical component of the magnetic field, shown in Figure 19a, was taken from the Wave-CNN and from the SW-NE oriented section C1-C2. The magnetic section is mainly from the areas where the K13, K20 and K23 
soundings were located. The geological section (Figure 21a) is added below the magnetic section (Figure 21b). It was observed that the magnetic anomalies were high in the regions where the iron ore is concentrated.

Drill hole KM10 had very high magnetic anomaly values; the ore is $20 \mathrm{~m}$ thick and not covered by any sediments in this section and was determined to be $95 \mathrm{~m}$ thick. Therefore, the observed ore anomalies indicate high values.

\section{RESULTS}

The new Wave-CNN method combines CNNs and wavelet methods. It has been used in recent years in geophysical engineering to distinguish regional-residual anomalies and to determine structural boundaries. Backpropagation algorithms and wavelet theory have been used in a learning algorithm developed in the CNN method. In the current study, the Wave-CNN method was first compared with the validity of the method used with synthetic data (Figure 7 and 9). After successful results were obtained with the synthetic data, a field study was carried out on the iron ore deposits of the Avnik region surveyed by the General Directorate of mineral research and exploration (MTA).

The Wave-CNN method was applied to the magnetic anomaly maps in the area of iron ore in the Gonactepe, Heylandere and Miskel regions. The acquired Wave-CNN anomaly maps were compared with drilling results from the study regions. High-grade polarisation was found near the surface in the Gonactepe vertical component of the magnetic field. High anomalies are usually located between $-24,000 \mathrm{nT}$ and 25,000 nT (Figure 13). Mines are located near the surface in high anomaly areas. In addition, low anomaly values located in the Gonactepe region were seen in the G1, G6, G13 and G21 drill holes. The anomaly had a very low value in the G1 drill hole. It is accepted that if the anomaly value is low, there should be no high-grade ore. Figure 17 shows that the Wave-CNN output from drill hole G6 had high values. The G6 drill hole results show 4.0 $\mathrm{m}$ of sediment, $2.6 \mathrm{~m}$ of medium grade ore and $12 \mathrm{~m}$ of lowgrade ore. The G13 drilling site results showed $4.4 \mathrm{~m}$ of sediment; $2.2 \mathrm{~m}$ of low-grade ore, $4.5 \mathrm{~m}$ of high-grade ore and $9 \mathrm{~m}$ of medium grade ore, with apatite. Figure 17 shows that the anomaly value is low in drill hole G13. Figure 17 indicates that the Wave-CNN output and drill hole G13 show good agreement. The G21 drill hole results indicate $5.00 \mathrm{~m}$ of sediment; $5.0-11.0 \mathrm{~m}$ of medium grade ore with apatite above $11 \mathrm{~m}$ of sediment. Figures 13a and b show wave-CNN output. The mine is close to the surface where high anomalies are found. Drill 21 was made where the anomaly values were not visible and no mine was found. It is thought that if an anomaly value is high, this indicates high-grade ore. In Figure $15 \mathrm{~b}$, the magnetic anomaly section, A1-A2, is compared with the geological section from Figure 15a. It shows that the geological section and the magnetic section show good agreement with each other.

The Haylandere region contains a strong magnetic anomaly, as shown in Figure 16. The Wave-CNN output magnetic anomaly map shows an effect in two magnetic field bands coming from $\mathrm{H} 1 \mathrm{~A}$ drilling just outside of a strong anomaly that indicated approximately 40-50 m of gneiss and mica (Figure 17). Below $60 \mathrm{~m}$, the ore is found in bands and has no economic value. The $\mathrm{H} 9$ drill hole, also located in the Haylandere region, showed a strong magnetic anomaly, and the drilling encountered a thickness of approximately $29 \mathrm{~m}$ of massive magnetite ore (Figure 17). Approximately $20 \mathrm{~m}$ of ore was observed to create a strong anomaly effect. Due to the influence of the ore in this area, a strong anomaly is present.
Anomalies with high magnetic values were observed in the vertical component of the magnetic field of the Mişkel region (Figure 19a). The reason for this is that iron ores that create strong anomalies are close to the surface. The Wave-CNN method was applied to the vertical component of the magnetic field of the Miskel region: the second iteration result is shown in Figure $19 \mathrm{~b}$ and the fourth iteration is shown in Figure 19c. As the number of WaveCNN output iterations increased, the high magnetic anomaly values became clearer. The Wave-CNN output had high magnetic properties and high tenor near the surface of the mine. The magnetic anomaly map based on the drilling data provides very important information (Figure 20). There is no anomaly in the KM1 drill hole (Figure 19). Based on these values, a small amount of lowgrade ore was interpreted. From the Wave-CNN where the KM2 sounding was located, it appeared that there was no strong anomaly value (Figure 19). When the KM2 drill hole was cut, no massive ore deposit was found, but a massive ore deposit was found when drilling the KM4 hole, at a depth of $70 \mathrm{~m}$ (Figure 20). Therefore, the effect of the anomaly on the Wave-CNN output seemed to be very low (Figure 19a, b). In the KM5 drill hole, amphibole schist was intersected, and low-grade ore was observed near the surface. Here, when the Wave-CNN output was examined, an anomaly that was not very strong was observed (Figure 19a, b). The KM9 sounding was drilled far beyond the location of the anomaly values obtained from the WaveCNN output. As seen from the KM9 drill hole, mica schist and gneiss with amphibole extend to a depth of approximately $180 \mathrm{~m}$, and below this is massive ore. Massive ore does not create a strong magnetic effect due to its deep root. The KM10 drill hole is located in the area of the highest value magnetic anomaly on the map. On the Wave-CNN output, the opening of the KM10 sounding was located where the strongest anomaly values are found. The KM10 drilling results indicate massive ore $20 \mathrm{~m}$ below the surface and approximately $60 \mathrm{~m}$ of gneiss with amphibole overlying $95 \mathrm{~m}$ of massive ore. The output of the WaveCNN was very strong and produced good results. Below the depth of the massive ore, mica schist and low-grade ore are found. The KM13 drill hole is sited at the centre of two high anomaly values determined as $17 \mathrm{~m}$ of low-grade ore and $20 \mathrm{~m}$ of massive ore. Here, the low anomaly values and the magnetic effect of the low-grade ore are not very high. KM16's location is shown in Figure 19 along with the output of the Wave-CNN and the effects of the low magnetic anomaly. Here, there is approximately $9 \mathrm{~m}$ of mica schist, between 9 and $70 \mathrm{~m}$ of high-grade ore, $40 \mathrm{~m}$ of gneiss with amphibole and up to $14 \mathrm{~m}$ of massive ore was intersected (Figure 20). The high anomaly values and massive ore were not intersected in the KM20 drilling location; approximately $8 \mathrm{~m}$ of mica schist and an $12 \mathrm{~m}$ band of massive ore was intersected. Therefore, the very high anomaly value was not observed in the Wave-CNN output. The location of drill hole KM22 and the results are shown in Figure 19. Here, approximately $20 \mathrm{~m}$ of mica schist and $120 \mathrm{~m}$ of massive ore were intersected in accordance with the high values of the magnetic anomaly. The KM23 drill hole site is located near high anomaly values. Here, approximately $8 \mathrm{~m}$ of mica schist and up to $90 \mathrm{~m}$ of high-grade ore mixed with massive ore were observed. The C1-C2 section was compared with the geological section after the output of the Wave-CNN (Figure 21). The high magnetic anomaly values are consistent with the geological cross-section (Figure 21).

\section{CONCLUSION}

In the Avnik region,apatite-rich iron ores bear are widespread and showing volcanic characteristics. Metavolcanic rocks and granotoids associated with iron ores were folded during Alpine orogeny. The iron ore is banded, massif and scattered across the study area. 
Magnetite, apatite and actiaolite are predominant minerals in large bed types. Magnetite formations are more common near the surface. Iron ores, which are very rich in apatite, were initially formed in volcanic environment. The presence of apatite and magnetite which are common together and the metavolcanites interlayered with them support this result.

The results of the field study produced a wide range of magnetic anomalies in the areas where the MTA vertical magnetic anomaly maps indicated magnetic effects. The Wave-CNN method produced very good residual anomaly maps, and when compared with drilling results, these high value anomalies produced the best results. Geological sections were modelled from the drilling data, and for comparison, magnetic profiles were taken from the geological sections; there was good agreement between the magnetic anomaly values and the geological sections. Dipole anomaly structures were considered as a results from the Wave-CNN outputs obtained from three different study sites in the Avnik region The DE method was applied on the results of these anomaly structures. The results are consistent with both geological cross-section and drilling data

\section{ACKNOWLEDGEMENT}

We are grateful to General Directorate of Mineral Research and Exploration (MTA) for permitting us to use the Magnetic anomaly data. In this study, Scilab 5.5.1, free and open source software (distributed under CeCILL license-GPL compatible) developed by Scilab Enterprises (http://www.scilab.org) was used for the computations.

\section{REFERENCES}

[1] Akansu AN, Haddad RA (1992) Multiresolution Signal Decomposition. Boston-USA

[2] Albora AM, Hisarli ZM, Ucan ON (2004) Application of Wavelet Transform to Magnetic Data Due to Ruins of Hittite Civilization in Turkey. Pure appl Geoph 161: 907-930.

https://doi.org/10.1007/s00024-003-2478-x

[3] Albora AM, Özmen A, Ucan ON (2001a) Residual Separation of Magnetic Fields Using a Cellular Neural Network Approach. Pure appl Geophys 158: 1797 1818. https://doi.org/10.1007/PL00001244

[4] Albora AM, Ucan ON (2001) Gravity Anomaly Separation using 2-D Wavelet approach and average depth calculate. Doğuș University Journal 3: 1-12. http://journal.dogus.edu.tr/index.php/duj/article/vi ew/222

[5] Albora AM, Ucan ON, Özmen A, Özkan T (2001b) Separation of Bouguer anomaly map using Cellular Neural Network. J Appl Geophys 46: 129-142. https://doi.org/10.1016/S0926-9851(01)00033-7

[6] Albora AM, Ucan ON, Aydoğan A (2007a) Modeling Potential Fields Sources in The Gelibolu Peninsula (Western Turkey) Using A Markov Random Field Approach. Pure appl geoph 164: 1057-1080. https://doi.org/10.1007/s00024-007-0203-x

[7] Albora AM, Bal A, Ucan ON (2007b) A new approach for border detection of Dumluca (Turkey) iron ore area: Wavelet Cellular Neural Networks. Pure appl geoph 164: 119-215. https://doi.org/10.1007/s00024-006-0156-5
[8] Alp H, Albora AM, Tur H (2011) A view of tectonic structure and gravity anomalies of Hatay region southern Turkey using Wavelet Analysis. J Appl Geoph 75:498-505.

https://doi.org/10.1016/j.jappgeo.2011.07.004

[9] Balkaya Ç (2013) An implementation of differential evolution algorithm for inversion of geoelectrical data. J Appl Geoph 98: 160-175. https://doi.org/10.1016/j.jappgeo.2013.08.019

[10] Balkaya Ç, Ekinci YL, Göktürkler G, Turan S (2017) 3D non-linear inversion of magnetic anomalies caused by prismatic bodies using differential evolution algorithm. J Appl Geoph 136: 372-386. https://doi.org/10.1016/j.jappgeo.2016.10.040

[11] Boschetti F, Hornby P, Horowitz FG (2001) Wavelet based inversion of gravity data. Exploration Geophysics 32: 48-55 https://doi.org/10.1071/EG01048

[12] Chua LO, Roska T (2002) Cellular Neural Networks and Visual Computing. Foundation and Applications, Cambridge UK, Cambridge University Press

[13] Chua LO, Yang L (1988) Cellular Neural Networks: Theory. IEEE Trans. On Circuits and Systems 35: 12571272. doi:10.1109/31.7600

[14] Çelebi H (1985) Die Genese der Magnetit-ApatitLagerstatte Avnik, Provinz Bingol/ Türkei und ihre wirtschaftsgeologische Bewwrtung. Doctorate thesis, Berlin University

[15] Çelebi H (1989) Ansatze zur Rohstoffwirtschaftlichen Bewwrtung der Magnetit-Apatit-Lagerstatte Avnik, Ost-Türkei. Erzmetall 42: 78-85

[16] Davis A, Murshak A, Wiscombe W (1994) Waveletbased multi-fractal analysis of nonstationary and/or intermittent geophysical signals: In Wavelets in Geophysical (Eds. E. Foufoula Georgiou and P. Kumar) Academic Press, Inc, pp 249-298

[17] Daubechies L (1990) The Wavelet Transform TimeFrequency Localization and Signal Analysis. IEEE Trans: on Information Theory 36: 961-1005

[18] Ekinci YL (2016) MATLAB-based algorithm to estimate depths of isolated thin dike-line sources using higherorder horizontal derivatives of magnetic anomalies. Springer Plus 5: 1384

[19] Ekinci YL, Balkaya Ç, Göktürkler G (2019) Parameter Estimations from Gravity and Magnetic Anomalies Due to Deep-Seated Faults. Differential Evolution versus Particle Swarm Optimization. Turkish Journal of Earth Sciences 28: 860-881. doi:10.3906/yer-1905-3

[20] Erdogan BF (1982) Geology and structural features of Bitlis Massif in Avnik (Bingol) region. Ege University, Faculty of Geosciences, Institute of Science and Technology.

[21] Erdogan B, Dora 00 (1983) Geology and genesis of the apatite bearing iron deposits of the Bitlis Massif. Bulletin of the Geological Society of Turkey 26: 133134 
[22] Essa KS, Munschy M (2019) Gravity data interpretation using the particle swarm optimization method with application to mineral exploration. Journal of Earth System Science 123: 1-16. https://doi.org/10.1007/s12040-019-1143-4.

[23] Essa KS, Elhussein M (2018) PSO (Particle Swarm Optimization) for interpretation of magnetic anomalies caused by simple geometric structures. Pure appl geophys 175: 3539-3553. http://dx.doi.org/10.5772/intechopen.71086.

[24] Fedi M, Quarta T (1998) Wavelet Analysis for the regional-residual and local separation at potential field anomalies. Geophy Prospec 46: 507-525. https://doi.org/10.1046/j.1365-2478.1998.00105.x

[25] Fedi F, Florio G, Rapolla A (1998) 2.5 D modelling of Somma-Vesuvius structure by aeromagnetic data: Journal of Volcanology and Geothermal Research. 82: 239-247.https://doi.org/10.1016/S03770273(97)00067-X

[26] Fedi M, Florio G (2003) Decorrugation and removal of directional trends of magnetic fields by the wavelet transform: application to archaeological areas. Geophy Prospec 51: 261-272. https://doi.org/10.1046/j.1365-2478.2003.00373.x

[27] Grossman A, Morlet J (1985) Decomposition of functions into wavelets of constant shape and related transforms: and physics. Lectures on Recent Results (Ed.: L. Streit) World Scientific, Singapore.

[28] Hagan MT, Demuth HB, Beale MH (1995) Neural Networks Design: PWS Publishing Company Boston Massachusetts.

[29] Helvacı C (1984) Apatite-Rich Iron deposits of the Avnik (Bingol) Region, Southeastern Turkey. Economic Geology 79: 354-371. https://doi.org/10.2113/gsecongeo.79.2.354

[30] Helvacl C, Griffin WL (1983) Metamorphic Feldspathization of Metavolcanics and Granitoids, Avnik Area, Turkey. Contributions to Mineralogy and Petrology 83: 309-319.

[31] Hornby P, Boschetti F, Horvitz FG (1999) Analysis of potential field data in the wavelet domain. Geophysical Journal International 137: 175-196.

[32] Holden DJ, Archibald NJ, Boschetti F, Jessell MW (2000) Inferring Geological Structures using Wavelet-Based multiscale edge analysis and forward models. Exploration Geophysics 31: 67-71.

[33] Liu S, Hu X, Fedi M, Zhu M (2018) Forward and inverse modelling of magnetic data under complex magnetism effects. International Symposium on Deep Earth Exploration and Practices. Beijing China.

[34] Matsumoto T, Chua LO, Yokohama T (1990) Image Thinning with a Cellular Neural Network. IEEE Transactions on Circuits and Systems 37: 638-640.

[35] Osman 0, Albora AM (2015) Modeling of Gravity Anomalies due to 2D Geological Structures using Genetic Algorithm. IU-Journal of Electrical \& Electronics Engineering 15: 1929-1935.
[36] Osman O, Albora AM, Ucan ON (2007) Forward modelling with Forced Neural Networks for gravity anomaly Profile. Math Geol 39: 593-605. https://doi.org/10.1007/s11004-007-9114-8

[37] Rao RM, Bopardikar AS (1998) Wavelet Transforms Introduction to Theory and Applications. Reading MA: Addison Wesley Longman, USA.

[38] Ridsdill-Smith TA, Dentith MC (1999) The wavelet transforms in aeromagnetic processing. Geophysics 64: 1003-1013. https://doi.org/10.1190/1.1444609

[39] Slot K, (1992) Cellular Neural Network Design for Solving Specific Image-Processing Problems. International Journal of Circuit Theory and Applications 20: 629-637.

[40] Storn R (1996) On the usage of differential evolution for function optimization. 1996 Biennial Conference North American Fuzzy Information Processing Society, Berkeley, CA, pp 519-523.

[41] Storn R, Price K (1997) Differential evolution a simple and efficient heuristic for global optimization over continuous spaces. Journal of Global Optimization 11: 341-359.

[42] Telford WM, Geldart LP, Sheriff RE, Keys DA (1990) Applied Geophysics. Cambridge University Press.

[43] Ucan ON, Bilgili E, Albora AM (2002) Magnetic Anomaly Separation using Genetic Cellular Neural Networks. Journal of the Balkan Geophysical Society 3: 65-70.

[44] Ucan ON, Seker S, Albora AM, Ozmen A (2000) Separation of Magnetic Field Data Using 2-D Wavelet approach. Journal of the Balkan Geophysical Society 3: 53-58. 
TABLE AND FIGURES

TABLE 1. Parameters of dipoles $\mathrm{z}=$ upper depth; $\alpha=$ angle; $\mathrm{L}=$ length; $\mathrm{x}=$ distance.

TABLE 2. Parameters of three different prisms (Inclination $I=60$, Denclination $D=20$ ).

TABLE 3. Estimated model parameters calculated using DE method from cross-sections obtained as a result of Wave-CNN output of field data.

FIGURE 1. The architecture of Wave-CNN method.

FIGURE 2. A cellular neural network in $4 \times 4$ dimension.

FIGURE 3. Piece-wice linear output function of CNN.

FIGURE 4. Dynamic model of a CNN (The matrices A and B are cloning templates. A acts on the output of neighbouring cells and is as the feedback operator. B in turn effects the input control and is as the control operator. A constant bias I and the cloning templates determine the transient behaviour of the cellular nonlinear network).

FIGURE 5. Mexican hat wavelet function for $a=0.1$ and $b=2$ coefficients.

FIGURE 6. Polarized Magnetic Dipole Model.

FIGURE 7. Synthetic example for five dipoles

a) The total magnetic dipole anomaly map of Table I (contour interval is $0.5 \mathrm{nT}$ ).

b) The second vertical derivative method (contour interval is $0.5 \mathrm{nT} / \mathrm{unit}^{2}$ ).

c) Downward method (contour interval is $0.5 \mathrm{nT}$, downward 1 unit)

d) Upward method (contour interval is $0.1 \mathrm{nT}$, upward 2 unit)

e) Wave-CNN output of Total magnetic anomaly map (first iteration, Contour interval is $0.03 \mathrm{nT}$ ).

f) Wave-CNN output of Total magnetic anomaly map (third iteration, Contour interval is $0.03 \mathrm{nT}$ ).

FIGURE 8. Prisms with three different parameters.

FIGURE 9. Three prisms the total magnetic anomaly

a) contour map of Table II (contour interval is $50 \mathrm{nT}$ ).

b) Shaded relief map.

c) Derivative shaded relief map.

d) Edge detection Analytic signal shaded Relief map.

e) Edge detection horizontal gradient shaded Relief map.

f) Wave-CNN output of shaded Relief map (first iteration).

FIGURE 10. Flowcharts showing the main processing steps of the DE algorithm (Ekinci et al 2019).

FIGURE 11. Location map of Bingöl region at the Turkey (The study area is shown in the box of Bingöl-Avnik region).

FIGURE 12. Bingol iron ore (Avnik region) Geology and Location map (Helvacı and Griffin (1983) has been changed

FIGURE 13. Gonactepe located in the hills a) vertical component of the magnetic field (contour interval is $3600 \mathrm{nT}$ ) b) Wave-CNN output of Gonactepe vertical magnetic anomaly map (A1-A2 cross section, second iteration, Contour interval is $0.07 \mathrm{nT}$ ) c) Wave-CNN output of Gonactepe vertical magnetic anomaly map (third iteration, Contour interval is $0.07 \mathrm{nT}$ ) d) Model using DE algorithm from Wave-CNN output of the vertical component of the magnetic field anomaly map of a certain area.

FIGURE 14. Drilling Logs of the Gonactepe iron ore reserves.

FIGURE 15. Gonactepe area

a) Vertical geological section of A1-A2 profile

b) Vertical Magnetic anomaly cross-section of A1-A2 profile.

FIGURE 16. Heylandere region

a) Vertical magnetic anomaly map (contour interval is $1000 \mathrm{nT}$ )

b) Wave-CNN output of Heylandere vertical magnetic anomaly map (A1-A2 cross section, second iteration, Contour interval is $0.02 \mathrm{nT}$ )

c) The model of the section using vertical component of the magnetic field anomaly map.

FIGURE 17. Vertical drilling sections of Heylandere region.

FIGURE 18. Heylandere region

a) Vertical geological section of B1-B2 profile (Helvacı (1984) has been changed from)

b) Vertical Magnetic anomaly cross-section of B1-B2 profile.

FIGURE 19. Miskel located in the hills

a) vertical Magnetic anomaly map (contour interval is $2500 \mathrm{nT}, \mathrm{C} 1-\mathrm{C} 2$ cross section)

b) Wave-CNN output of Miskel vertical magnetic anomaly map (second iteration, Contour interval is $0.02 \mathrm{nT}$ )

c) Wave-CNN output of Miskel vertical magnetic anomaly map (third iteration, Contour interval is $0.02 \mathrm{nT}$ )

d) Model structure from any section of the Wave-CNN output.

FIGURE 20. Drilling Logs of the Miskel iron ore reserves.

FIGURE 21. Miskel region

a) Vertical geological section of C1-C2 profile (Helvacı (1984) has been changed from)

b) Vertical Magnetic anomaly cross-section of C1-C2 profile.

TABLE 1: Parameters of dipoles $\mathrm{z}=$ upper depth; $\alpha=$ angle; $\mathrm{L}=$ length; $\mathrm{x}=$ distance.

\begin{tabular}{|l|c|c|c|c|c|}
\hline \multicolumn{1}{|c|}{ Parameters } & Dipole 1 & Dipole 2 & Dipole 3 & Dipole 4 & Dipole 5 \\
\hline (x,y) coordinate & 0,0 & 10,15 & $6,-10$ & $-15,10$ & $-10,10$ \\
\hline $\mathrm{Z}$ (deep) & 5 & 4 & 3.5 & 4.5 & 3 \\
\hline $\mathrm{L}$ (along) & 16 & 5 & 2 & 3 & 5 \\
\hline$\alpha$ (angle) & 20 & 90 & 60 & 80 & 70 \\
\hline
\end{tabular}


TABLE 2: Parameters of three different prisms (Inclination I=60, Denclination $D=20$ ).

\begin{tabular}{|c|c|c|c|c|c|c|}
\hline Prism Num. & X1 Coor. & X2 Coor. & Y1 Coor. & Y2 Coor. & h Top of Depth & $\begin{array}{c}\text { H Bottom of } \\
\text { Depth }\end{array}$ \\
\hline 1 & 10 & 25 & 10 & 20 & 2 & 5 \\
\hline 2 & 12 & 45 & 25 & 40 & 3 & 6 \\
\hline 3 & 30 & 45 & 40 & 45 & 2.5 & 6 \\
\hline
\end{tabular}

TABLE 3: Estimated model parameters by using Differential Evolution (DE) method. The sections are considered after Wave-CNN output of the field data.

\begin{tabular}{|l|c|c|c|}
\hline \multicolumn{1}{|c|}{ Parameters } & $\begin{array}{c}\text { Model } \\
\text { Gonactepe }\end{array}$ & $\begin{array}{c}\text { Model } \\
\text { Heylandere }\end{array}$ & Model Miskel \\
\hline $\mathrm{Z}$ (deep) & $3 \mathrm{~m}$. & $0.5 \mathrm{~m}$. & $35 \mathrm{~m}$. \\
\hline $\mathrm{L}$ (along) & $12 \mathrm{~m}$. & $70 \mathrm{~m}$. & $60 \mathrm{~m}$. \\
\hline$\alpha$ (angle) & $135^{0}$ & $150^{0}$ & $0^{0}$ \\
\hline
\end{tabular}

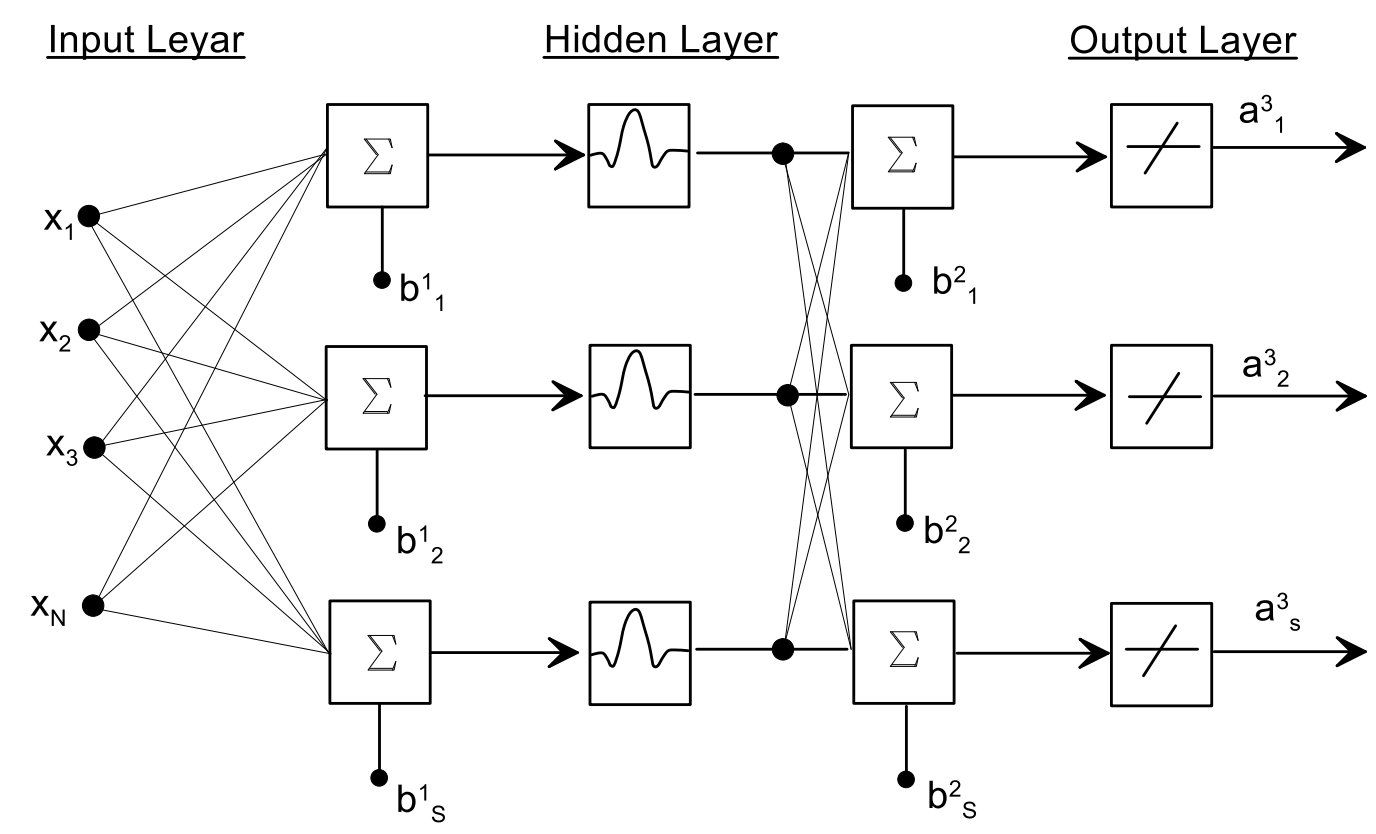

FIGURE 1: The architecture of Wave-CNN method.

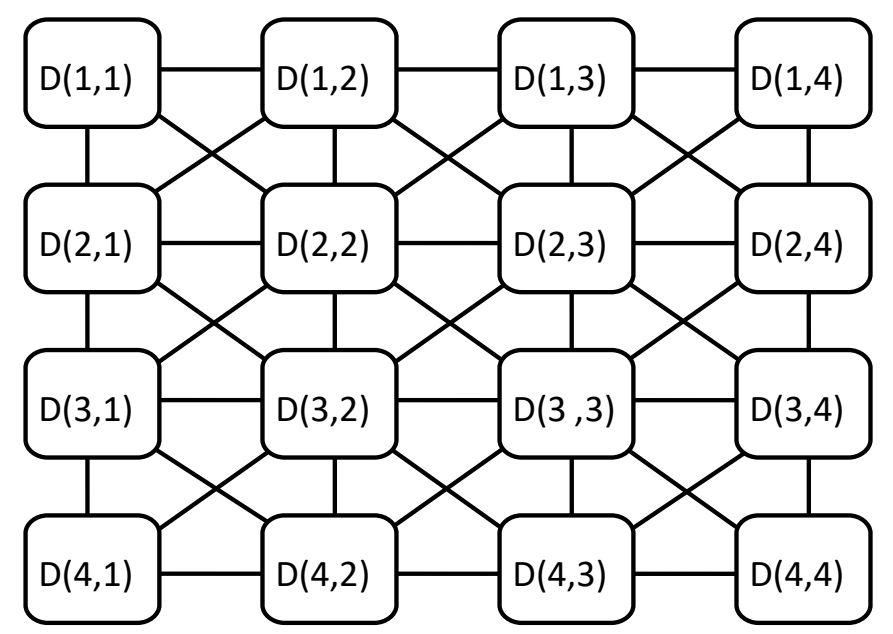

FIGURE 2: The illustration of a Cellular Neural Network in 4x4 dimension. 


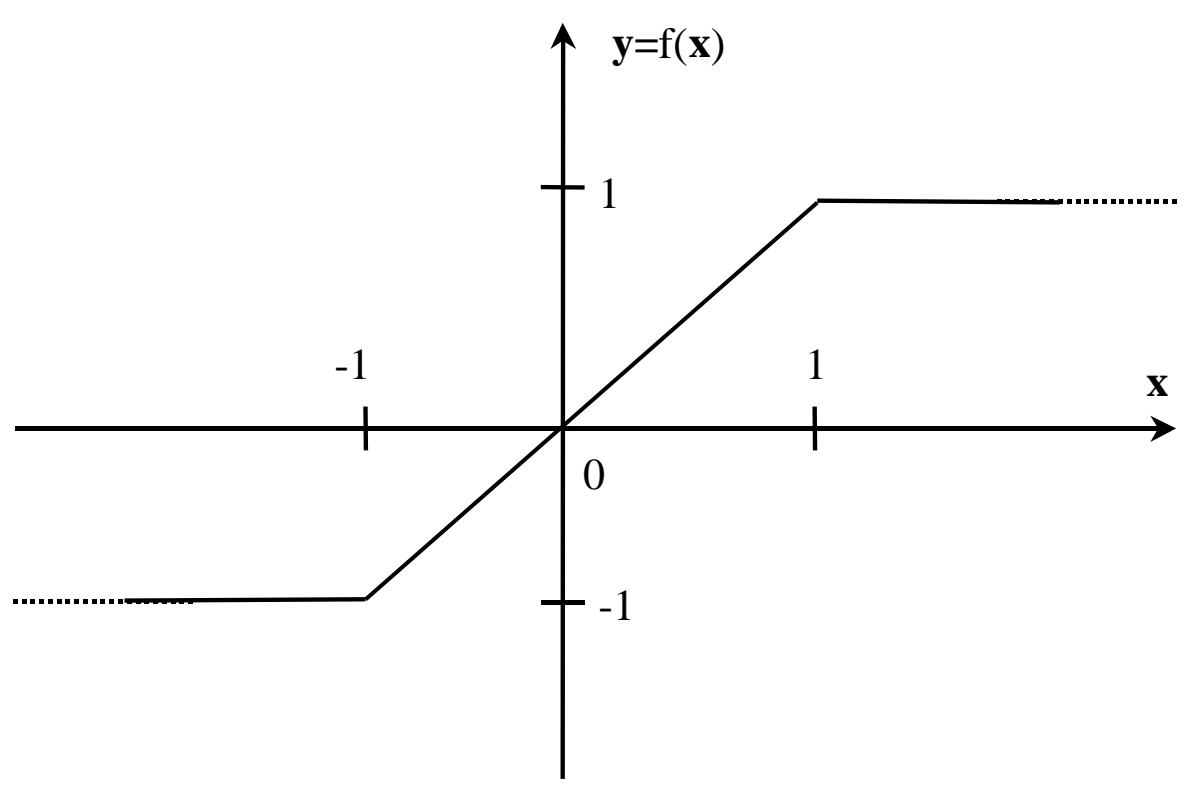

FIGURE 3: Piece-wice linear output function of CNN.

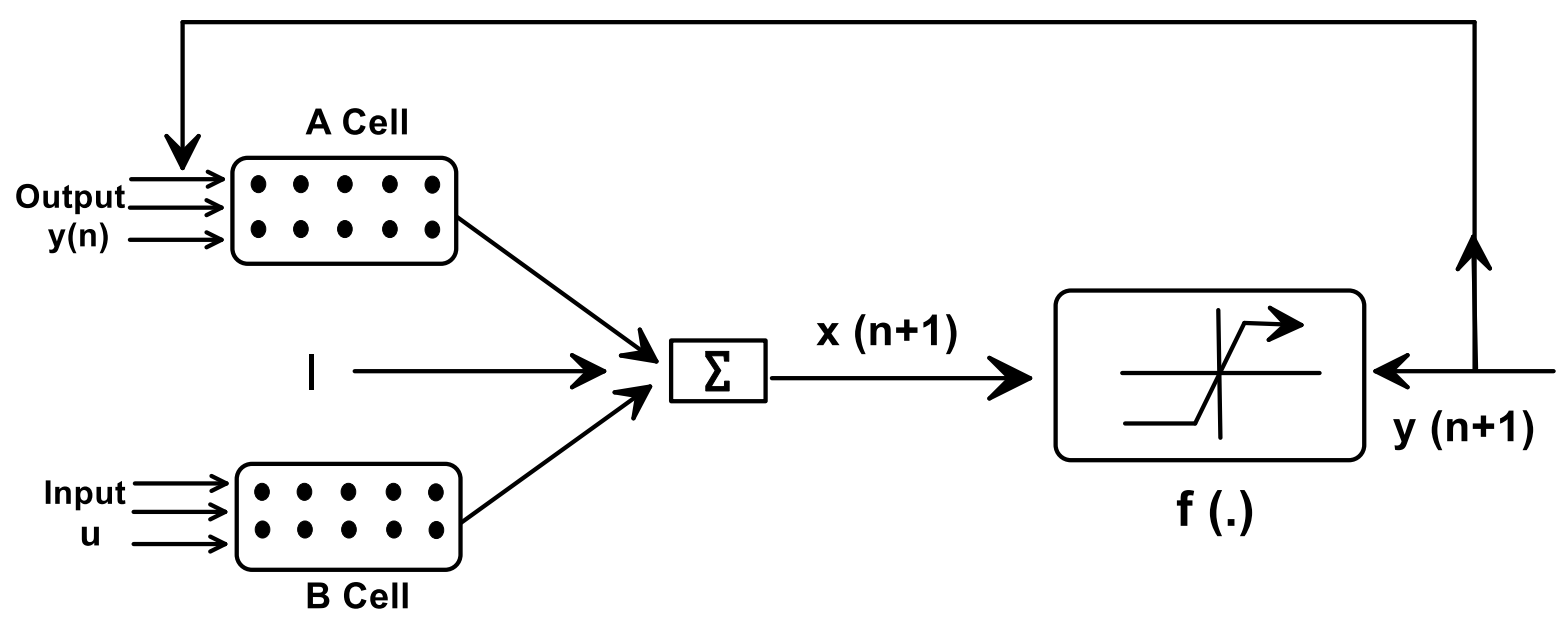

FIGURE 4: Dynamic model of a CNN (The matrices A and B are cloning templates. A acts on the output of neighbouring cells and is as the feedback operator. B in turn effects the input control and is as the control operator. A constant bias I and the cloning templates determine the transient behaviour of the cellular nonlinear network). 


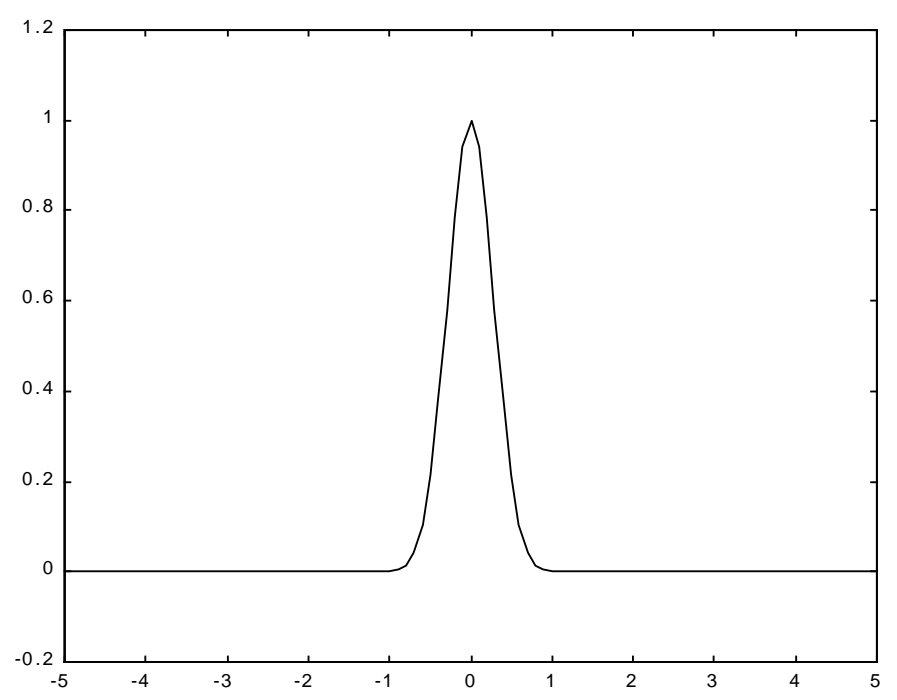

FIGURE 5: Mexican hat wavelet function for $\mathrm{a}=0.1$ and $\mathrm{b}=2$ coefficients.

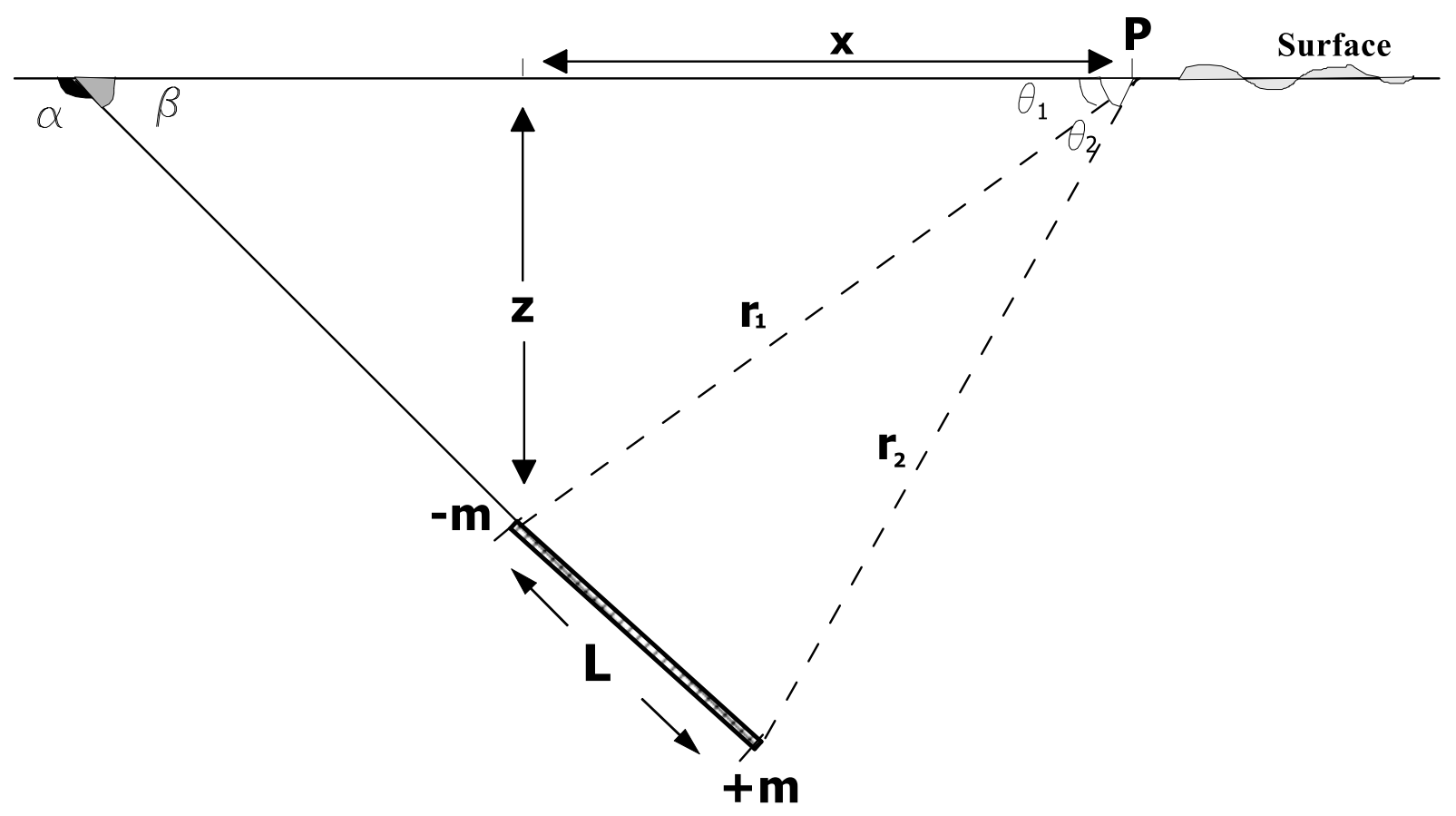

FIGURE 6: Polarized Magnetic Dipole Model. 


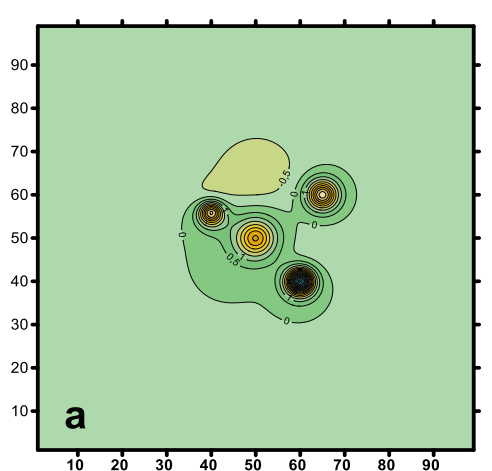

$\mathrm{nT}$ nT/unit ${ }^{2}$
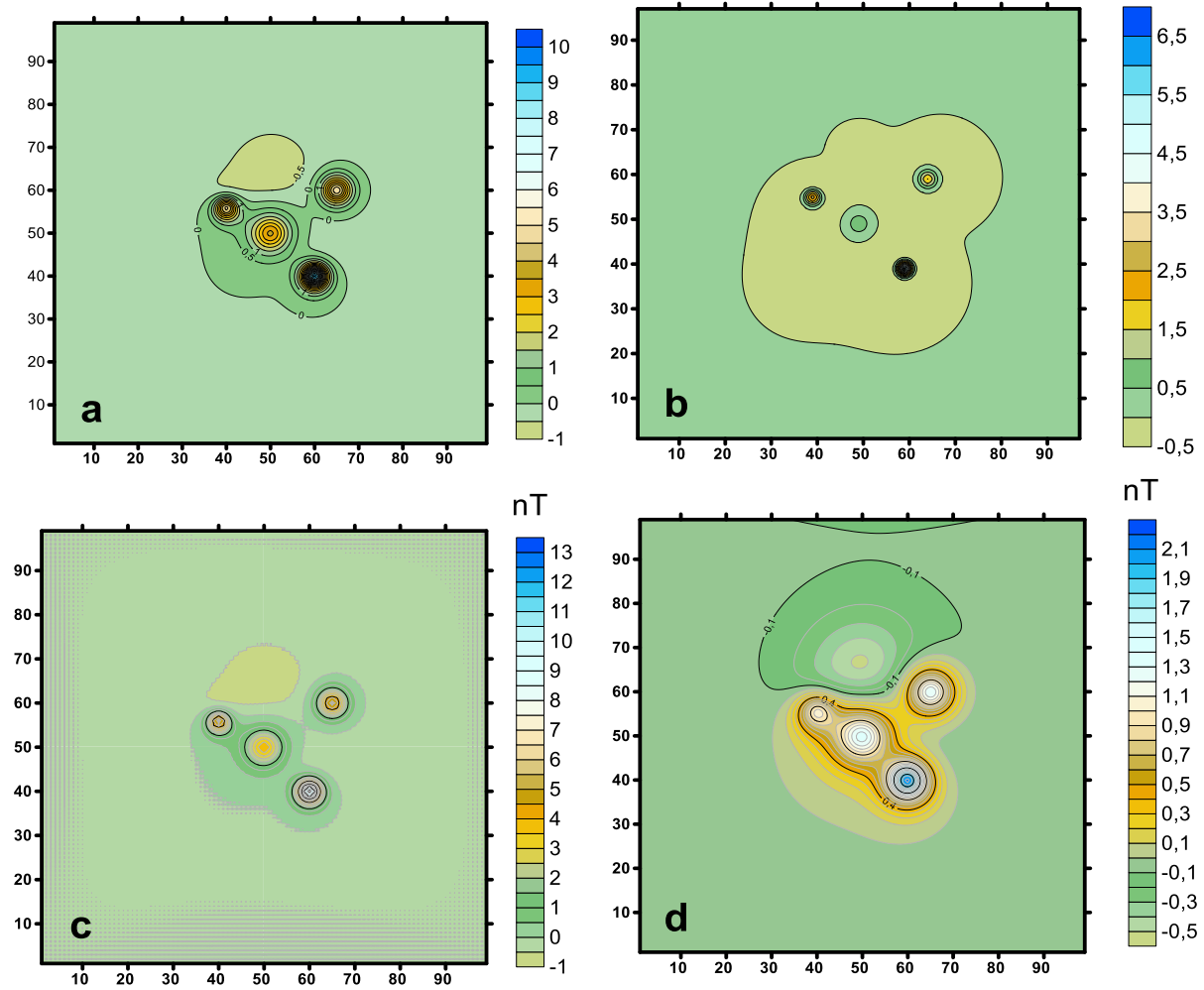

$\mathrm{nT}$

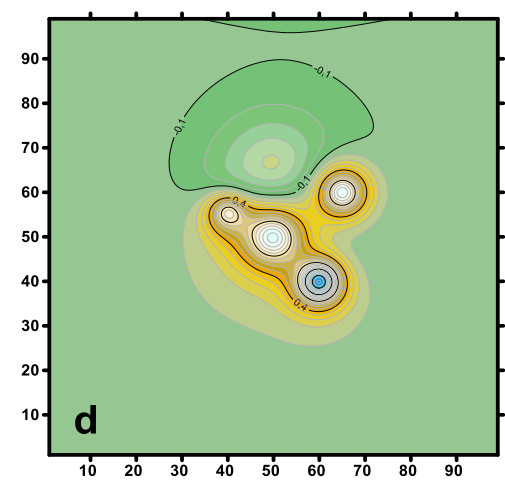

$\mathrm{nT}$
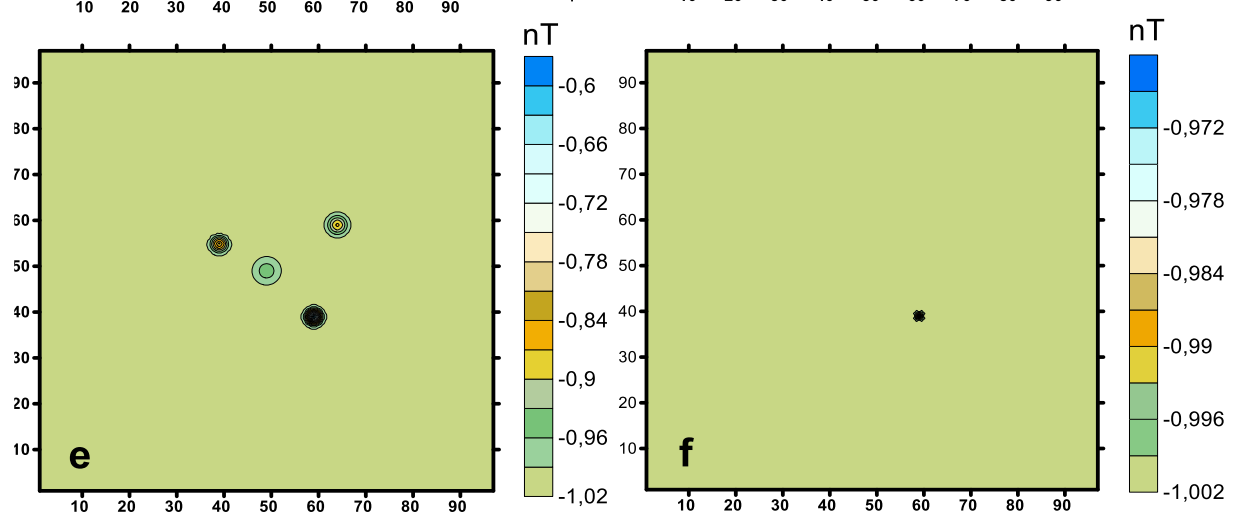

FIGURE 7: Synthetic example for five dipoles

a) The total magnetic dipole anomaly map of Table I (contour interval is $0.5 \mathrm{nT}$ ).

b) The second vertical derivative method (contour interval is $0.5 \mathrm{nT} / \mathrm{unit} 2$ ).

c) Downward method (contour interval is $0.5 \mathrm{nT}$, downward 1 unit)

d) Upward method (contour interval is $0.1 \mathrm{nT}$, upward 2 unit)

e) Wave-CNN output of Total magnetic anomaly map (first iteration, Contour interval is $0.03 \mathrm{nT}$ ).

f) Wave-CNN output of Total magnetic anomaly map (third iteration, Contour interval is $0.03 \mathrm{nT}$ ).

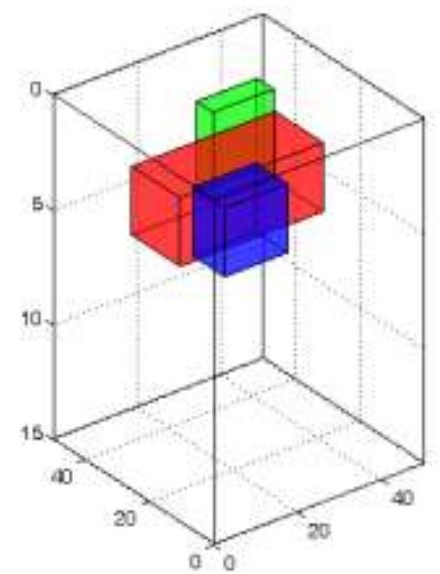

FIGURE 8: Prisms with three different parameters. 

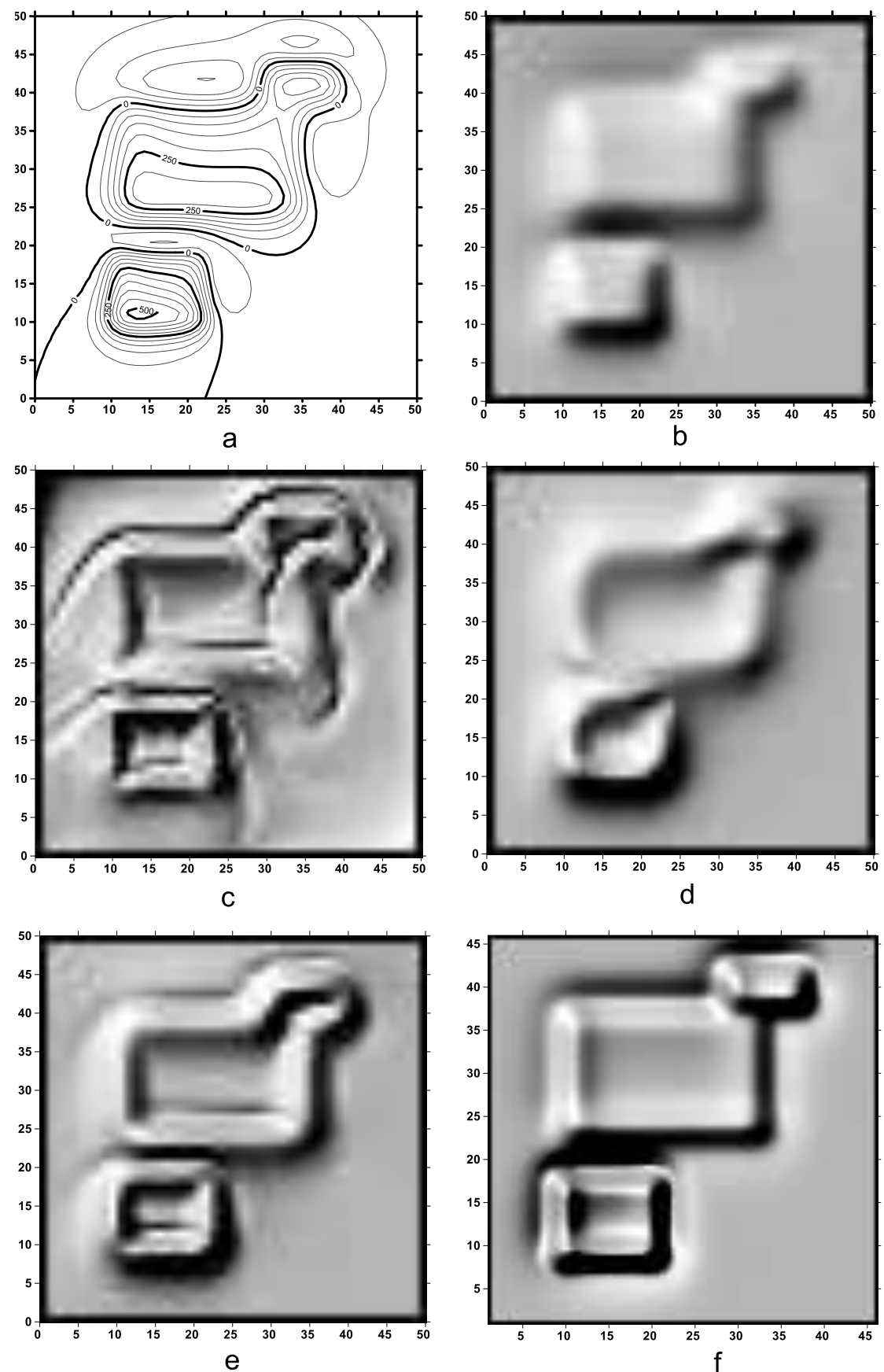

FIGURE 9: Three prisms the total magnetic anomaly

a) contour map of Table II (contour interval is $50 \mathrm{nT}$ ).

b) Shaded relief map.

c) Derivative shaded relief map.

d) Edge detection Analytic signal shaded Relief map.

e) E) Edge detection horizontal gradient shaded Relief map.

f) Wave-CNN output of shaded Relief map (first iteration). 


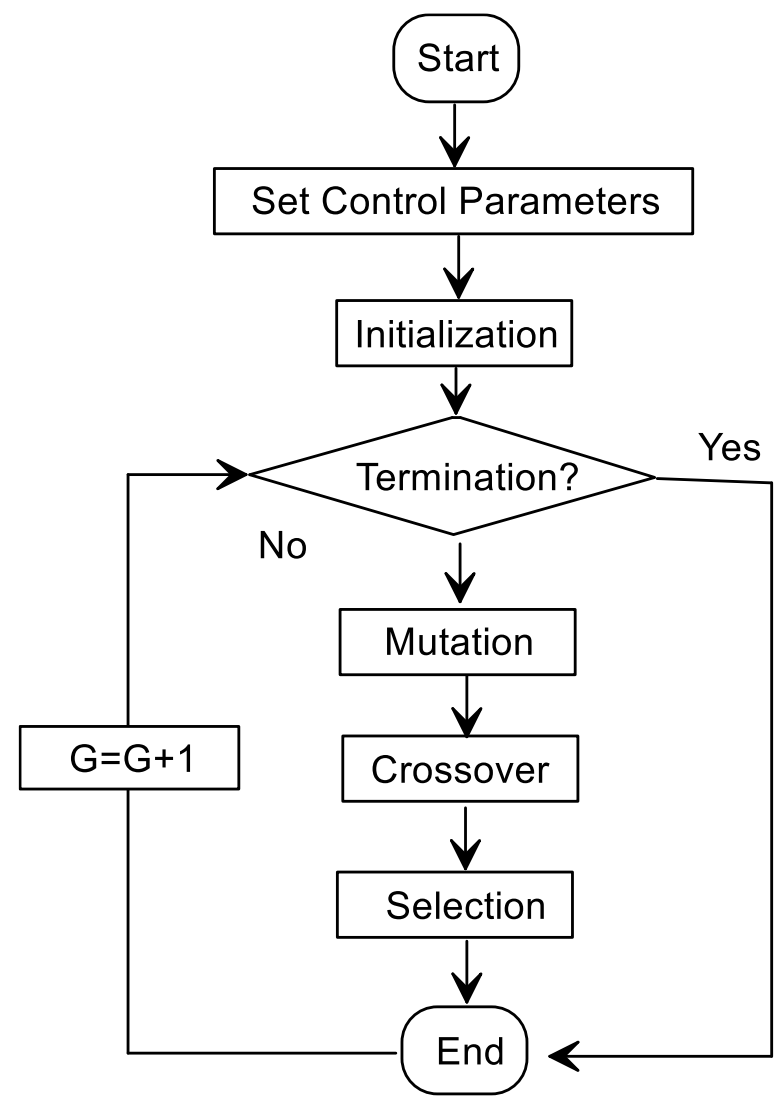

FIGURE 10: Flowcharts showing the main processing steps of the DE algorithm (Ekinci et al 2019).

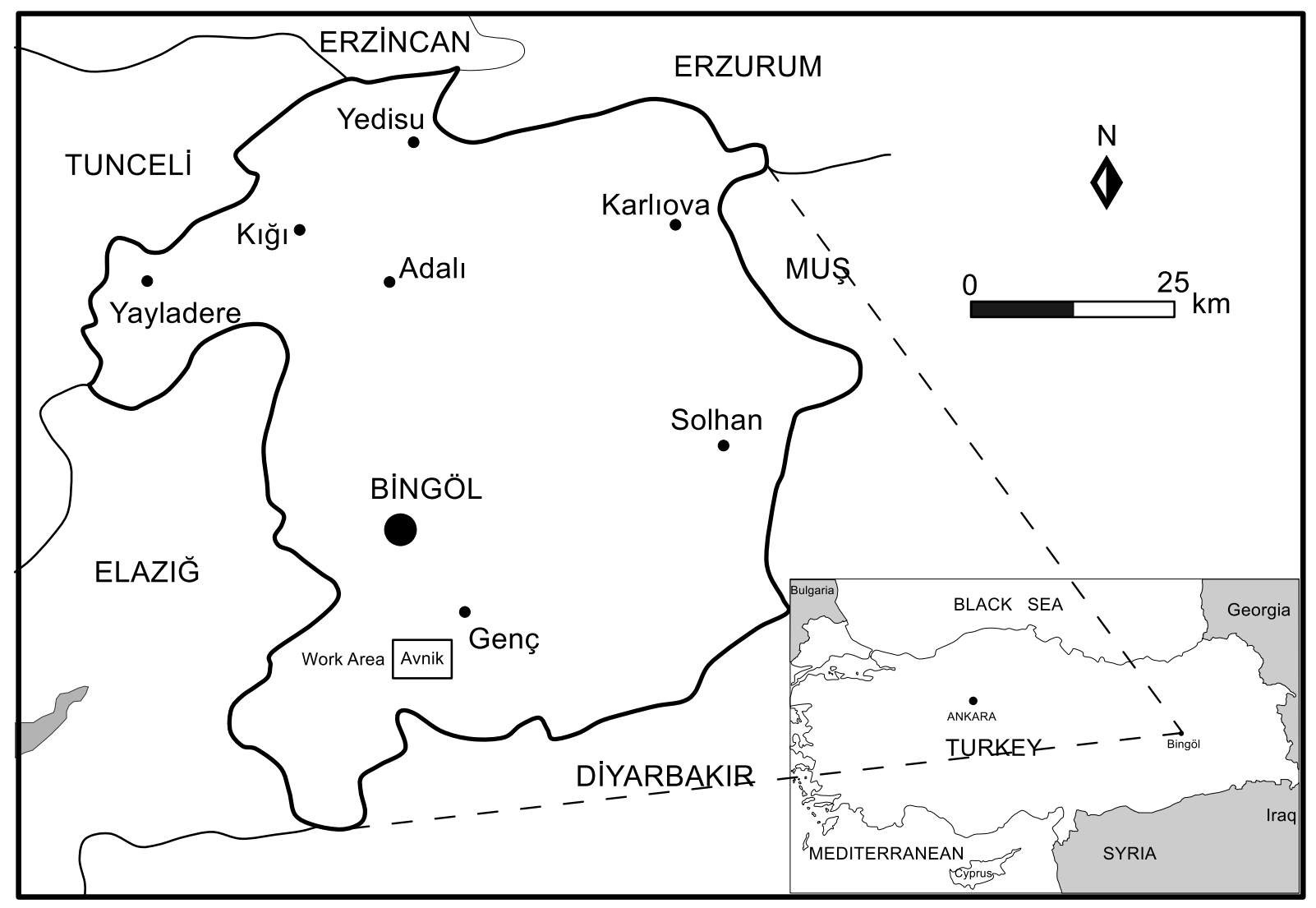

FIGURE 11: Location map of Bingöl region at the Turkey (The study area is shown in the box of Bingöl-Avnik region). 


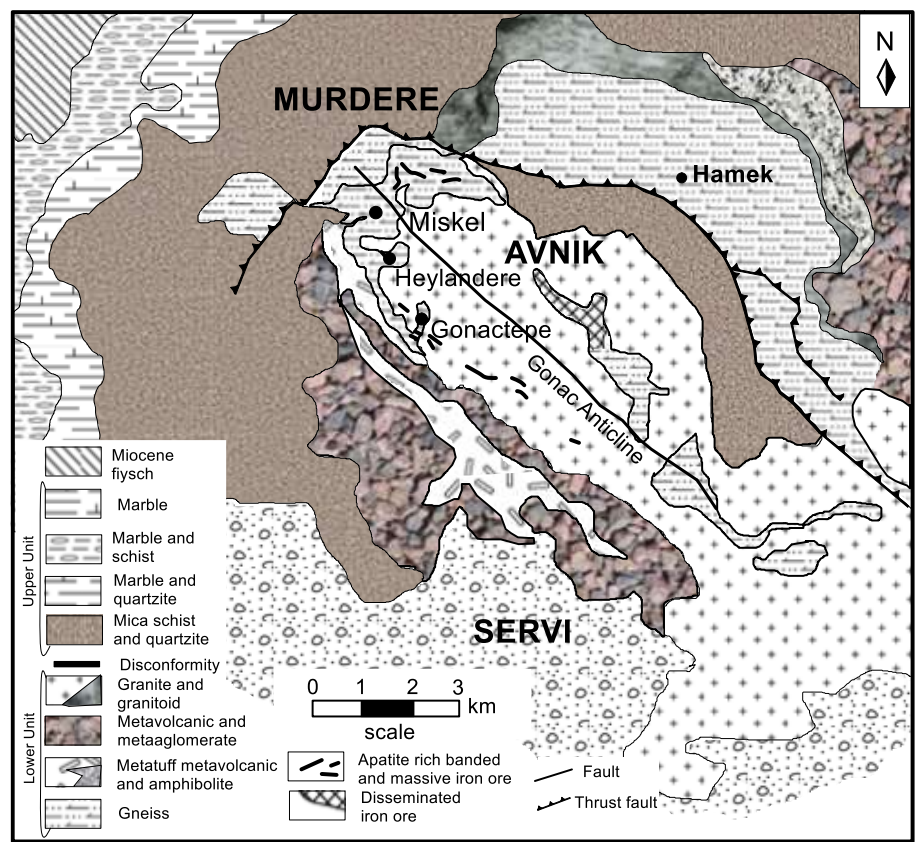

FIGURE 12: Bingol iron ore (Avnik region) Geology and Location map (Helvacı and Griffin (1983) has been changed.

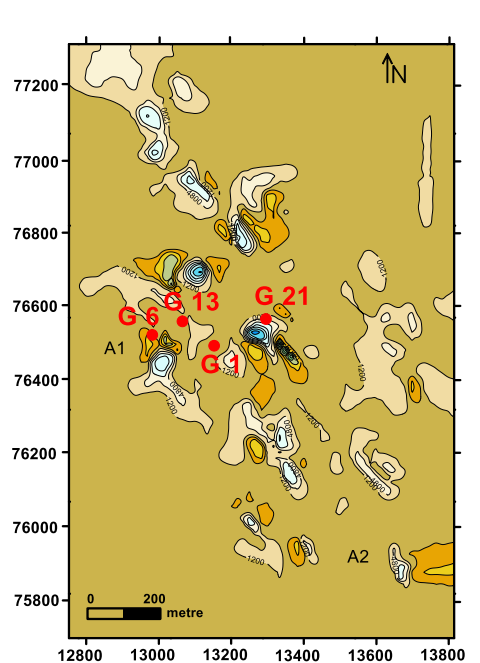

a

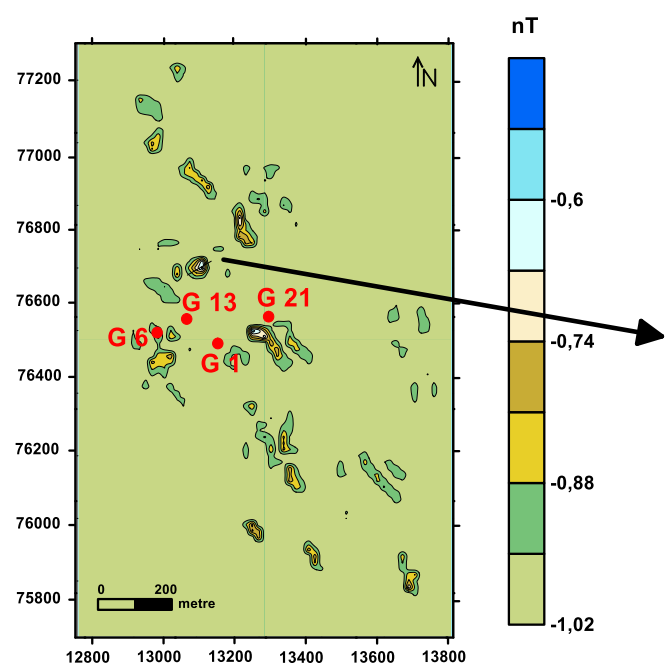

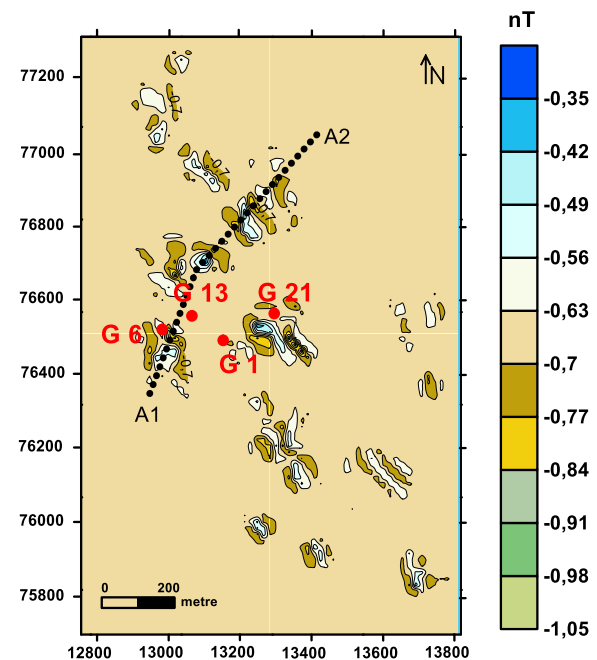

b
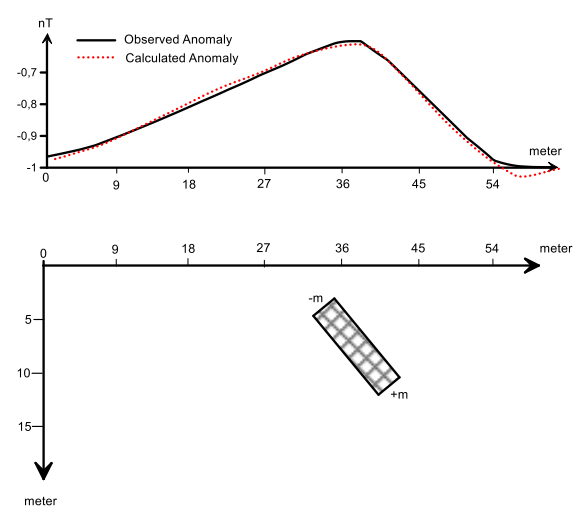

d

Figure 13. Gonactepe located in the hills

a) vertical component of the magnetic field (contour interval is $3600 \mathrm{nT}$ )

b) Wave-CNN output of Gonactepe vertical magnetic anomaly map (A1-A2 cross section, second iteration, Contour interval is $0.07 \mathrm{nT}$ )

c) Wave-CNN output of Gonactepe vertical magnetic anomaly map (third iteration, Contour interval is $0.07 \mathrm{nT}$ )

d) Model illustration using a certain section from Wave-CNN output of the vertical component of the magnetic field anomaly map as a result of DE algorithm. 


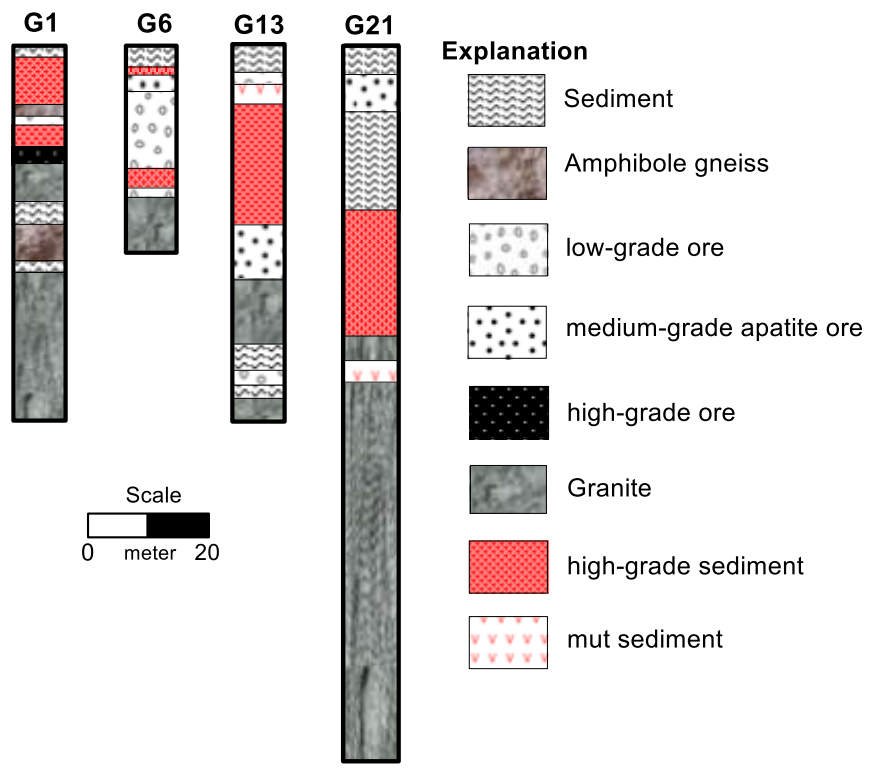

FIGURE 14: Drilling Logs of the Gonactepe iron ore reserves.

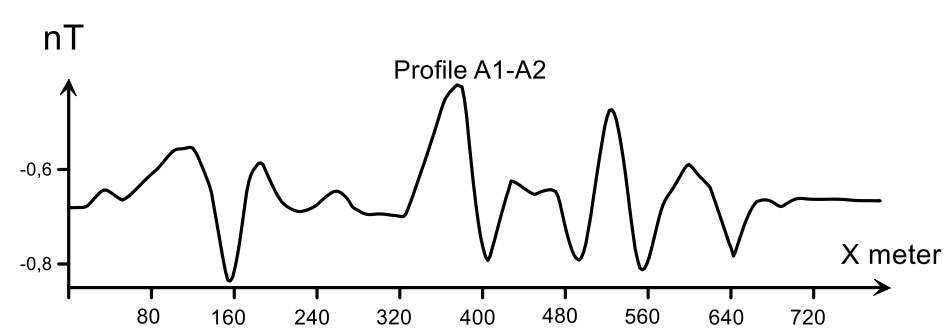

b

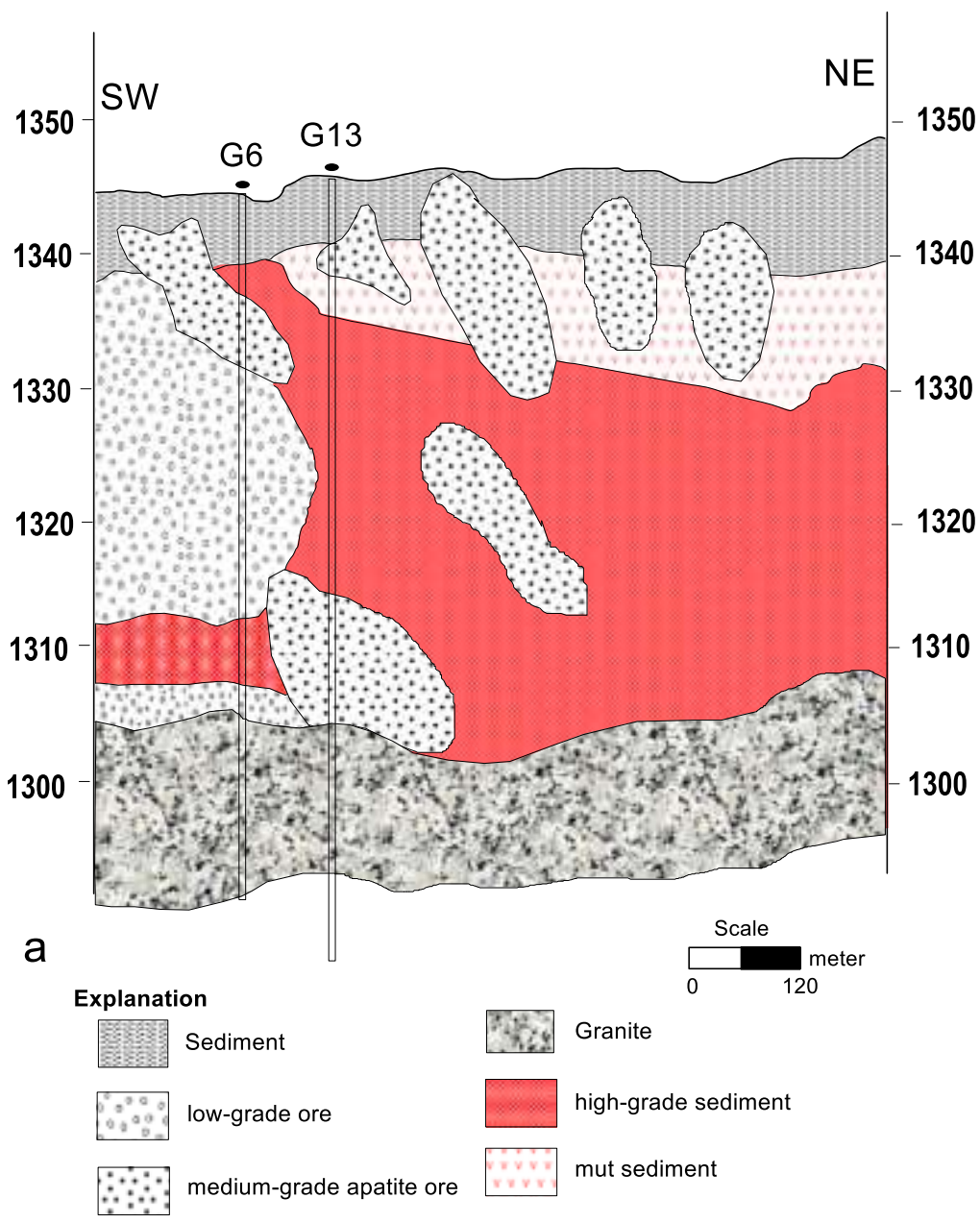

FIGURE 15: Gonactepe area a) Vertical geological section of A1-A2 profile b) Vertical Magnetic anomaly cross-section of A1-A2 profile. 

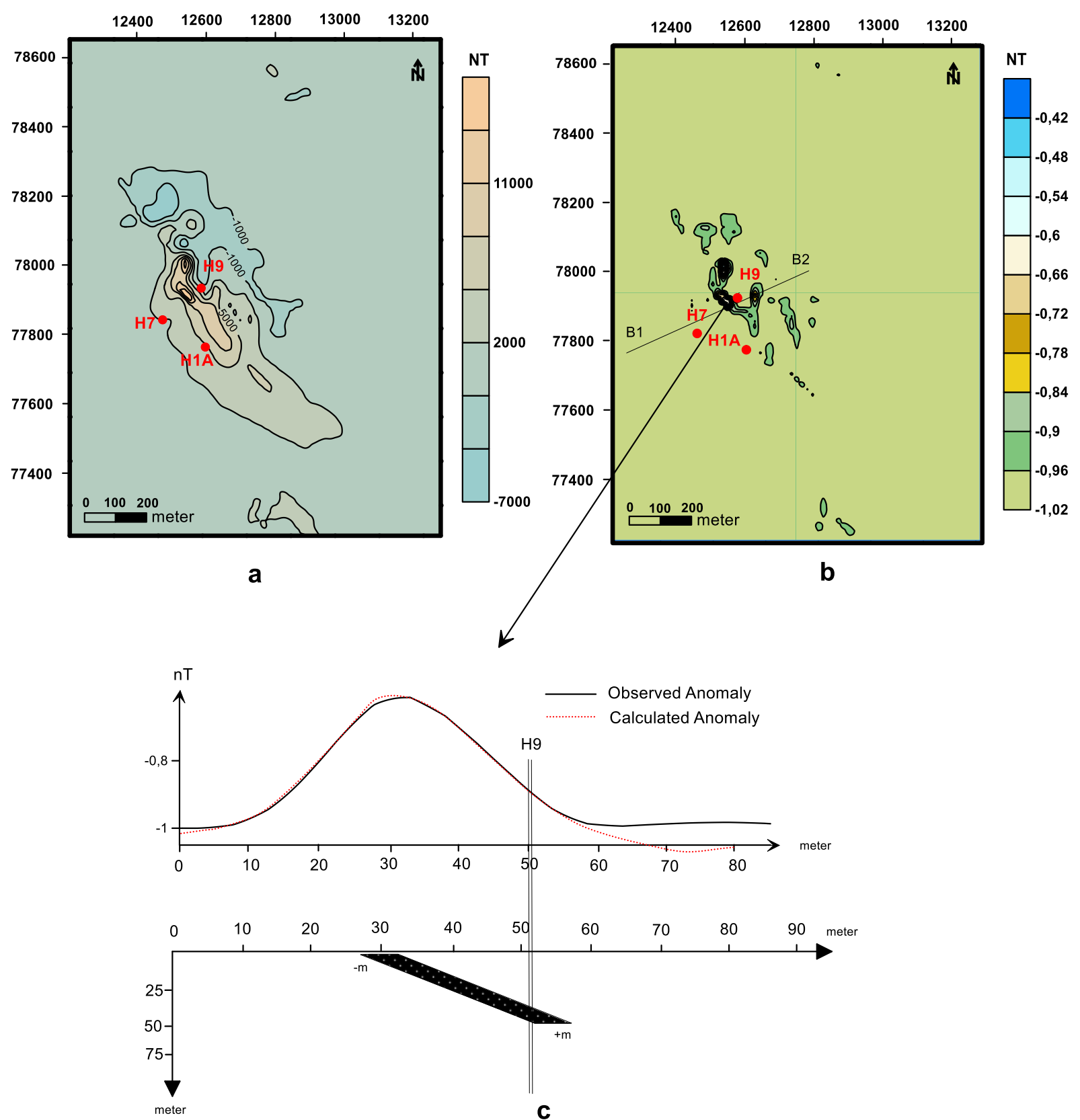

FIGURE 16: Heylandere region

a) Vertical magnetic anomaly map (contour interval is $1000 \mathrm{nT}$ )

b) Wave-CNN output of Heylandere vertical magnetic anomaly map (A1-A2 cross section, second iteration, Contour interval is $0.02 \mathrm{nT}$ )

c) Illustration of the model from a section of vertical component of the magnetic field anomaly map. 


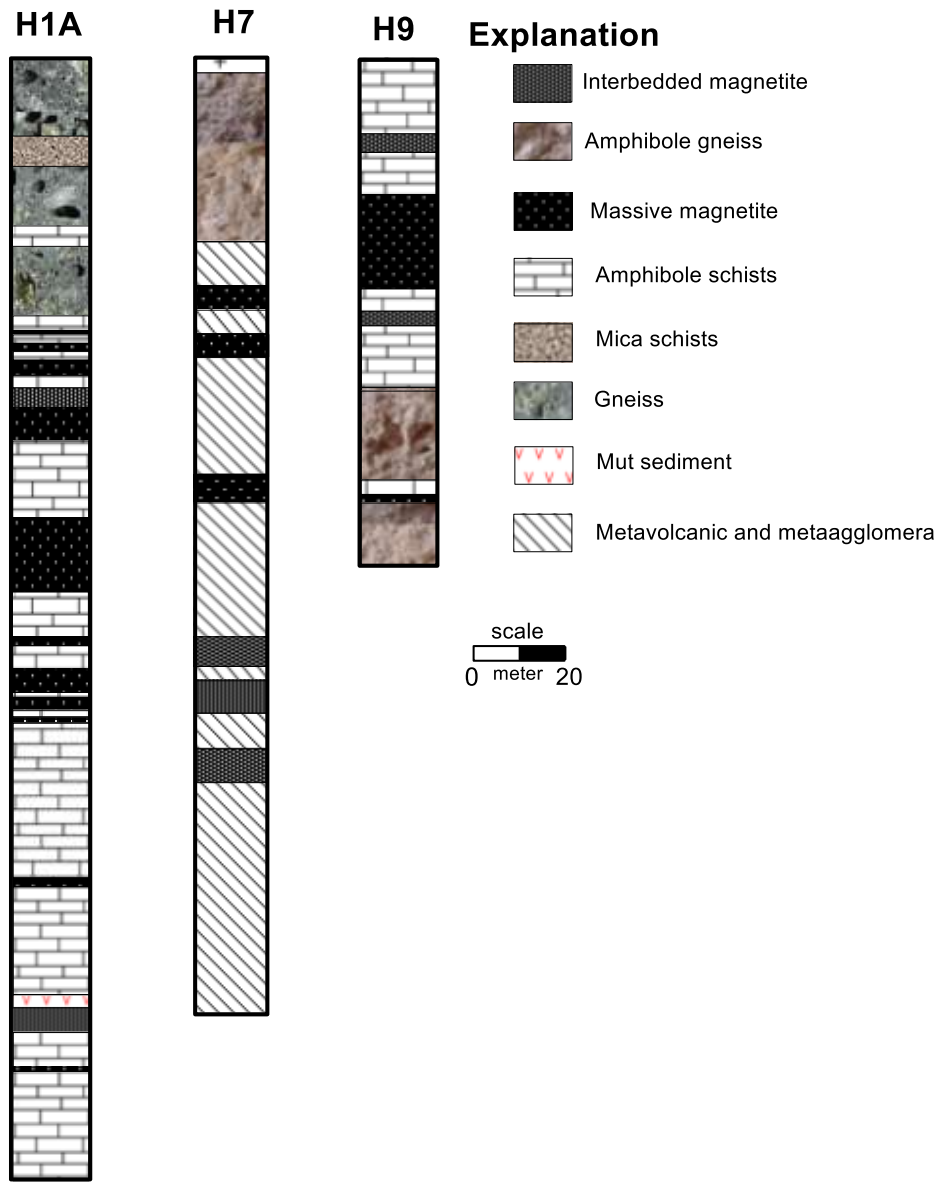

FIGURE 17: Vertical drilling sections of Heylandere region.

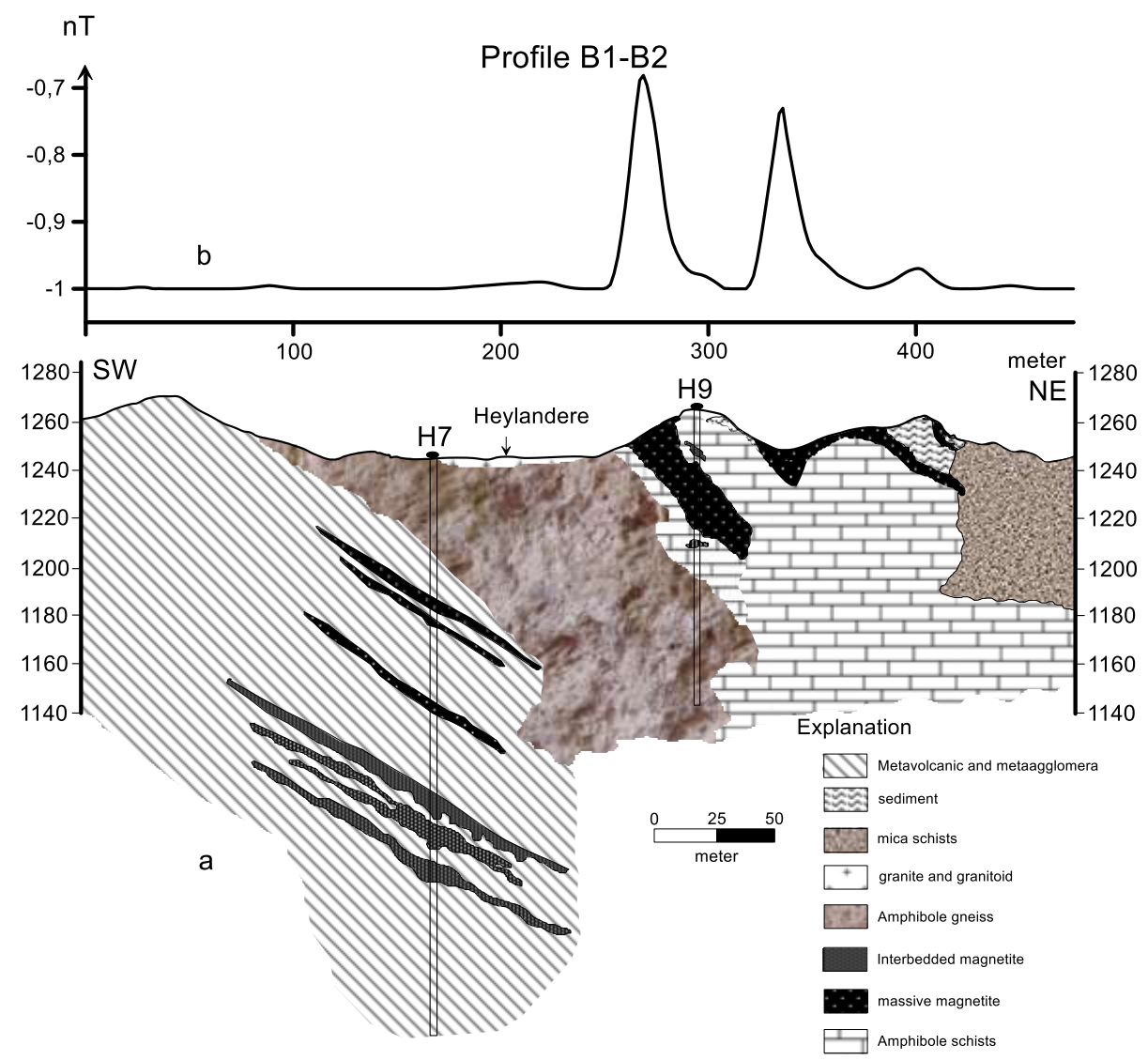

FIGURE 18: Heylandere region

a) Vertical geological section of B1-B2 profile (Helvacı (1984) has been changed from)

b) Vertical Magnetic anomaly cross-section of B1-B2 profile. 


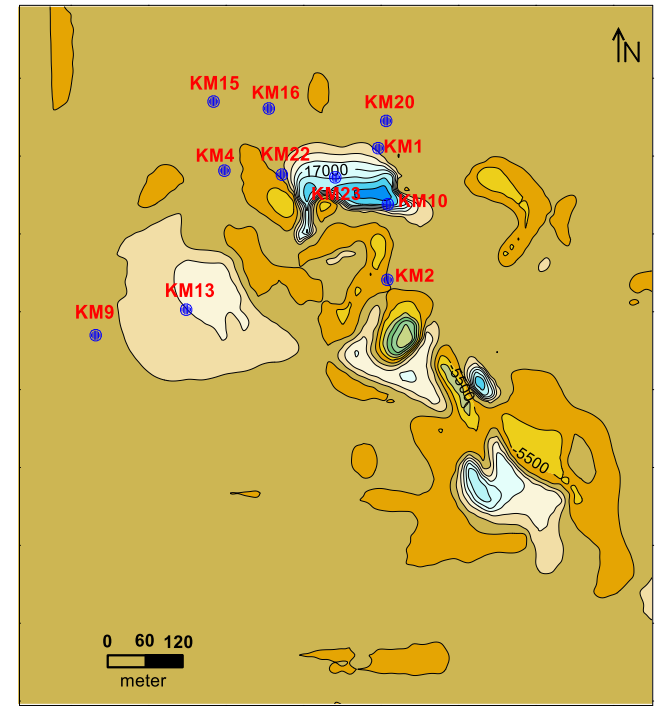

a

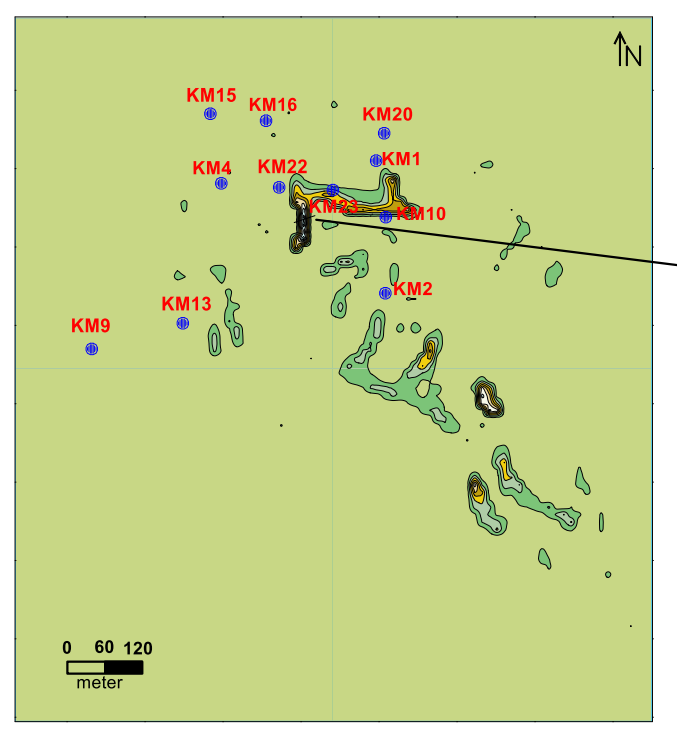

nT
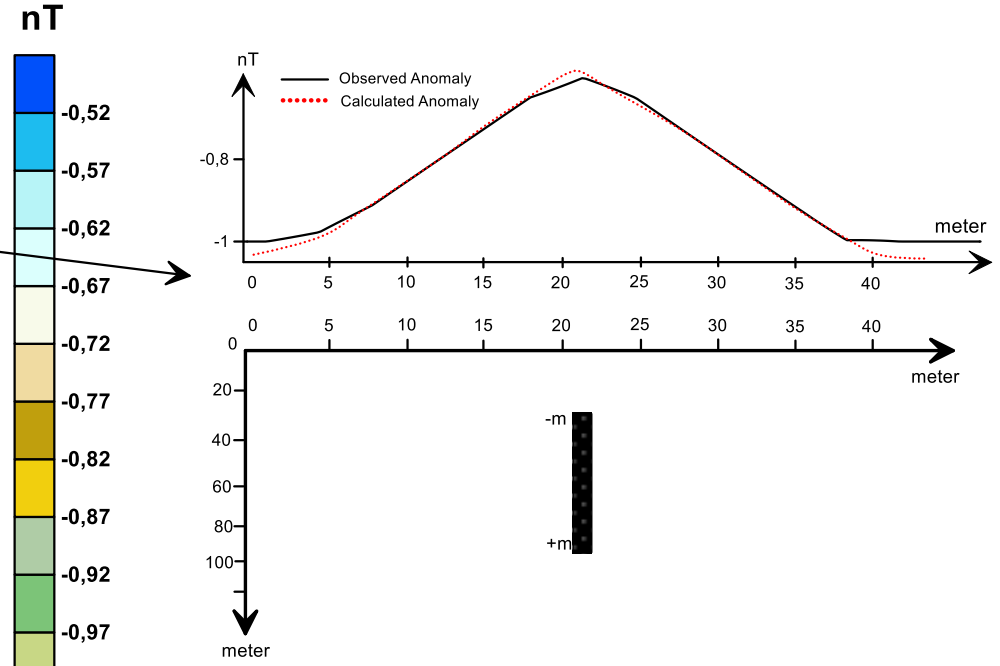

d

C

FIGURE 19: Miskel located in the hills

a) vertical Magnetic anomaly map (contour interval is $2500 \mathrm{nT}, \mathrm{C} 1-\mathrm{C} 2$ cross section)

b) Wave-CNN output of Miskel vertical magnetic anomaly map (second iteration, Contour interval is $0.02 \mathrm{nT}$ )

c) Wave-CNN output of Miskel vertical magnetic anomaly map (third iteration, Contour interval is $0.02 \mathrm{nT}$ )

d) Model structure of a any section using Wave-CNN output. 


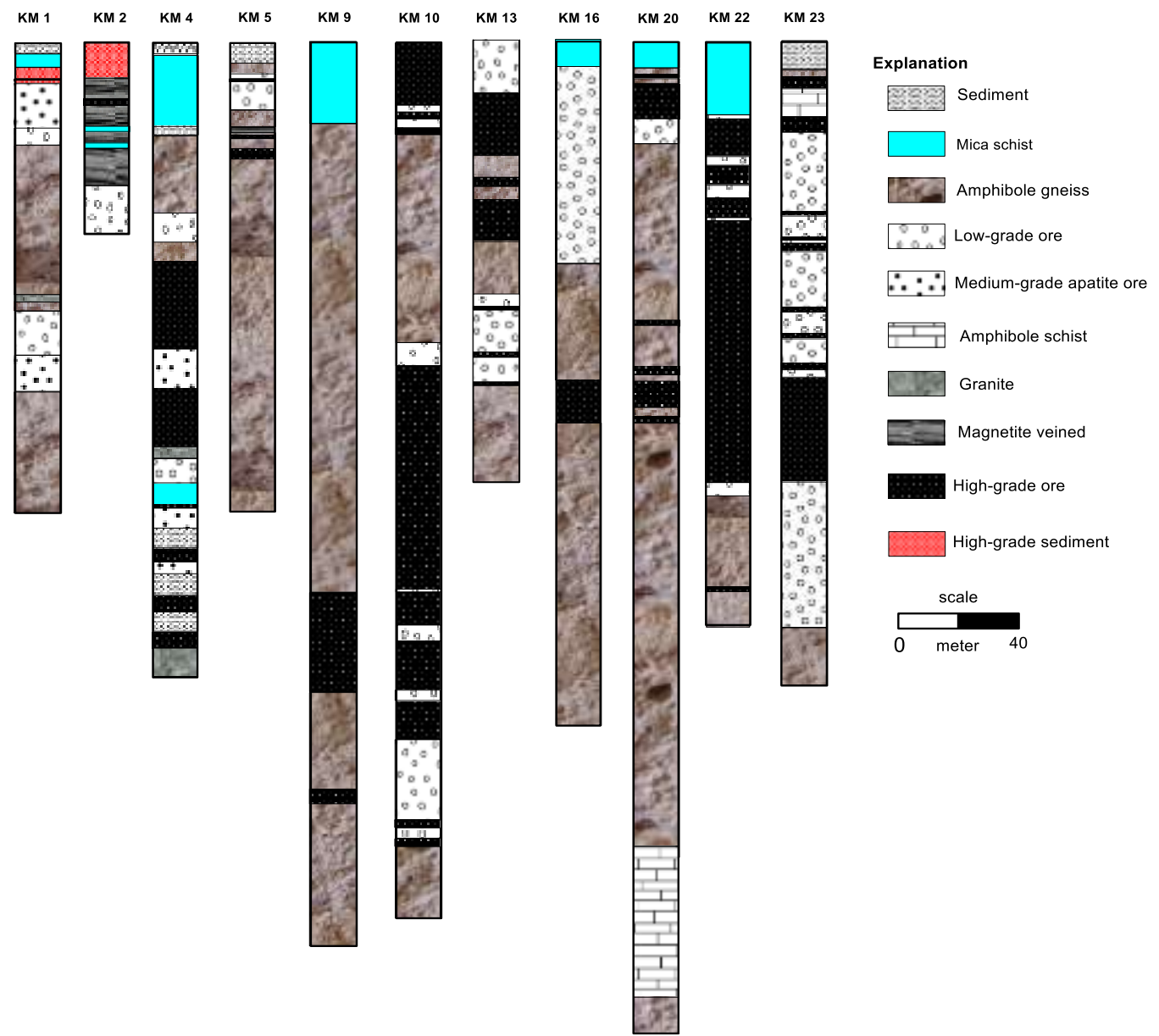

FIGURE 20: Drilling Logs of the Miskel iron ore reserves.
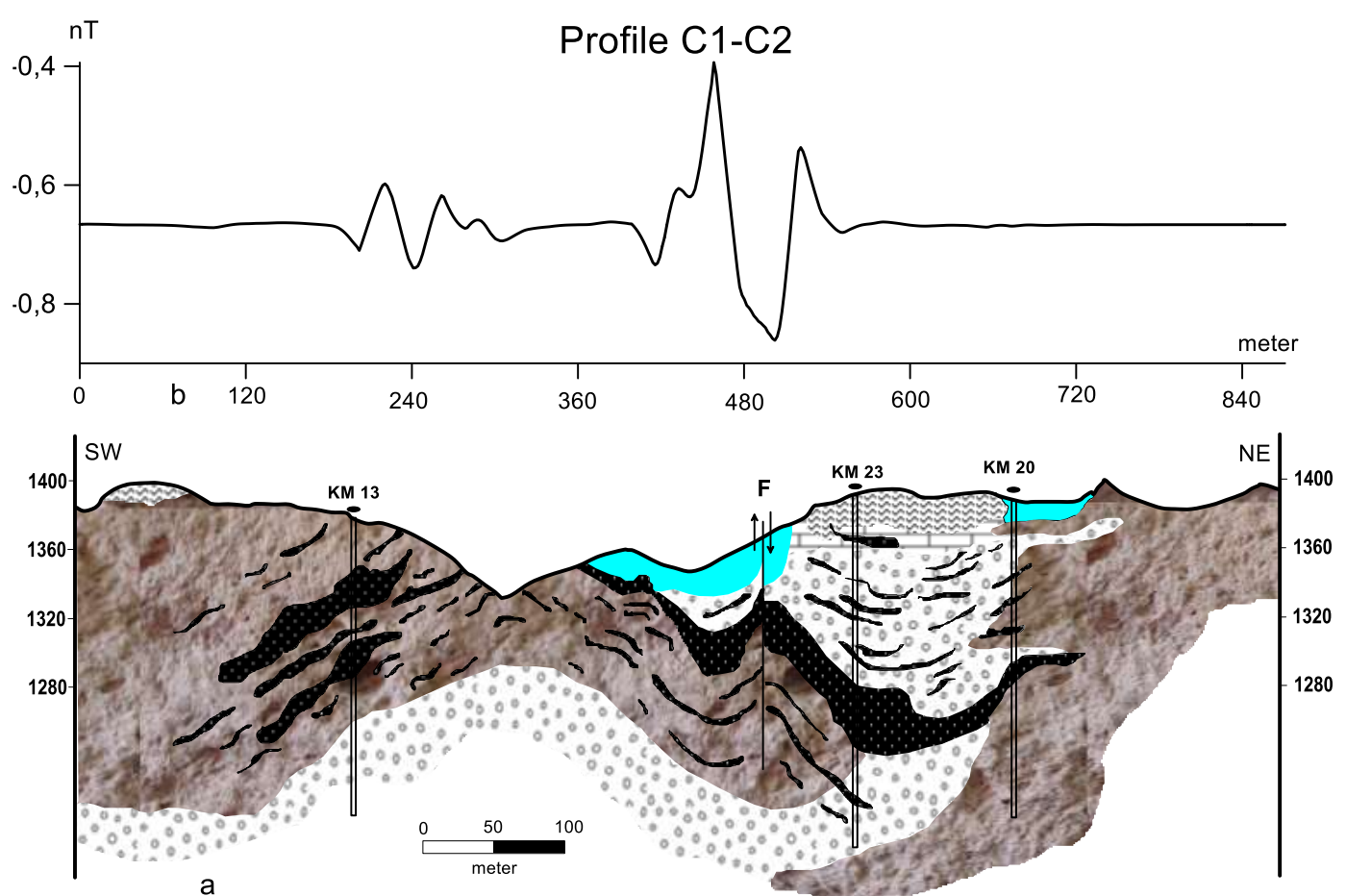

\section{Explanation}

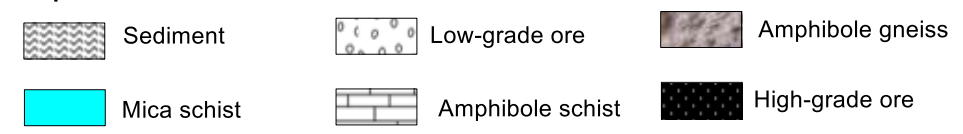

FIGURE 21: Miskel region

a) Vertical geological section of C1-C2 profile (Helvacl (1984) has been changed from)

b) Vertical Magnetic anomaly cross-section of C1-C2 profile. 